\title{
WestVirginiaUniversity
}

THE RESEARCH REPOSITORY @ WVU

Graduate Theses, Dissertations, and Problem Reports

2000

\section{Strawberry growth and fruit characteristics in response to coal bottom ash root media}

\author{
Donna Vae Coffindaffer Ballard \\ West Virginia University
}

Follow this and additional works at: https://researchrepository.wvu.edu/etd

\section{Recommended Citation}

Ballard, Donna Vae Coffindaffer, "Strawberry growth and fruit characteristics in response to coal bottom ash root media" (2000). Graduate Theses, Dissertations, and Problem Reports. 3174.

https://researchrepository.wvu.edu/etd/3174

This Dissertation is protected by copyright and/or related rights. It has been brought to you by the The Research Repository @ WVU with permission from the rights-holder(s). You are free to use this Dissertation in any way that is permitted by the copyright and related rights legislation that applies to your use. For other uses you must obtain permission from the rights-holder(s) directly, unless additional rights are indicated by a Creative Commons license in the record and/ or on the work itself. This Dissertation has been accepted for inclusion in WVU Graduate Theses, Dissertations, and Problem Reports collection by an authorized administrator of The Research Repository @ WVU.

For more information, please contact researchrepository@mail.wvu.edu. 


\title{
Strawberry growth and fruit characteristics in response to coal bottom ash root media
}

\section{Donna Vae Coffindaffer Ballard}

\author{
Dissertation \\ Submitted to the \\ College of Agriculture, Forestry, and Consumer Science \\ West Virginia University
}

In partial fulfillment for the degree of Doctor of Philosophy in Agricultural Sciences with emphasis in Horticulture

Division of Plant and Soil Sciences

Committee Members: Dr. Bradford Bearce, chair

Dr. Rajeev Arora

Dr. Morris Ingle

Dr. David Blaydes

Dr. Alan Sexstone

West Virginia University

Morgantown, West Virginia

May 2000

key words: Fragaria, ananassa, nutriculture, rockwool, coal bottom ash, fruit color, fruit flavor, plugs 


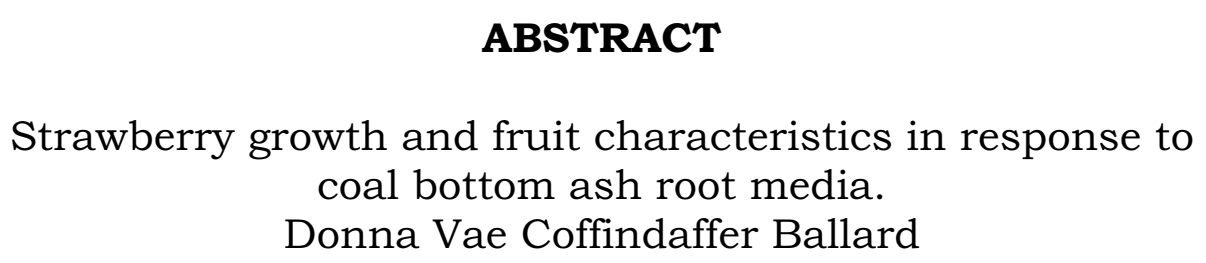

Commercial production of strawberry fruit during the off season offers greenhouse operators an alternative crop. Quality of such fruit may be influenced by production system. A series of studies evaluated various aspects of greenhouse production of strawberry fruit. In a study of commercially available strawberry seed rate of germination for $\mathrm{cv}$. 'Sweetheart', was enhanced by cutting the seed coat. Total germinated after 20 days was equal for the cut, the $4 \mathrm{x}$ and $8 \mathrm{x}$ sand paper scarification treatments. For cv. 'Fresca' the germination percentage was higher in plugs with Sunshine plug mix and Grodan Orchid Greenmix when compared to rockwool (RW) and rockwool plus coal bottom ash (CBA). In a nutriculture study of cv. 'Fresca' strawberries, vegetative growth was enhanced in CBA compared to RW. The next study of nutriculture grown cv. 'Fresca' found no significant differences in production measurements (days to first flower, days to first fruit, total number of flowers, and primary fruit fresh weight) due to substrate or nutrient solution strength. This study also found that color characteristics, internal/external chroma and hue, were responsive to both substrate and nutrient solution strength. The cv. 'Fresca' leaf and petiole tissue analysis showed above the recommended levels for calcium, boron, iron, manganese. Boron increased significantly in the Ft. Martin CBA grown plants. Repeating the nutriculture study with Ft. Martin CBA and RW control with commercially available cultivars (Cardinal, Crimson King, Earliglow, Honeoye, Surecrop, and Ozark Beauty) the number of crowns, number of leaves per plant, and fruit color measurements were determined by cultivar. Leaf area, leaf fresh weight, and leaf dry weight were reduced by the CBA. Leaf and petiole tissue analysis found supra-optimal levels of boron in all samples except 'Earliglow' in rockwool which had reduced boron. Gas chromatography flavor analysis for cv. 'Fresca' found the Pleasants and Ft. Martin CBA grown strawberries to be completely different from those grown in Albright CBA and the RW control. Cultivars, Cardinal and Honeoye, exhibited interaction with the media for flavor profiles. These studies show strawberry plant responses to varied cultural conditions and indicate the need for further nutrient/media studies and their link with flavor compound production.

Abbreviations used: $\mathrm{RW}=$ rockwool, $\mathrm{CBA}=$ coal bottom ash, $\mathrm{GC}=$ gas chromatograph 


\section{ACKNOWLEDGEMENTS}

Great appreciation is held for my family who supported this effort, usually without complaint, Geoff, Devin and Shannon Ballard.

To Norma and Bill Coffindaffer, thank you for instilling the desire for knowledge and the personal character to pursue the previous and current degrees. Also for the unlimited child care for Devin and Shannon.

Thank you Dr. Bearce for the support, guidance, occasional shove and most of all friendship. You are a true mentor and the University will be poorer for your retirement.

To my committee members who have encouraged and supported this study, thank you.

Special thank you to the greenhouse staff, Sue Myers, Gail Sikorsky, and Carol McCarthy, you have endured the time and space requirements of this study. They provide a unique refuge from the demanding atmosphere found outside their domain.

To those students who attended the classes I was privileged to teach, thank you for your attention in class, your determination to have certain classes taught, your support, and friendship.

Thank you to my fellow office-mates, as Kenny would say my co-"horts", for the conversations, problem-solving discussions, gripe sessions and friendship.

Thank you to Brian Tolka, Mike Kridle, and Henry Lee for their computer expertise and preparation of the figures that required scanning.

Thanks to the division of Resource Management for the use of the computer lab and the use of the SPSS statistical package.

To Dr. Stacy Gartin, thank you for the shoulder to cry on, the pats on the back, and just being a friend. 


\section{TABLE OF CONTENTS}

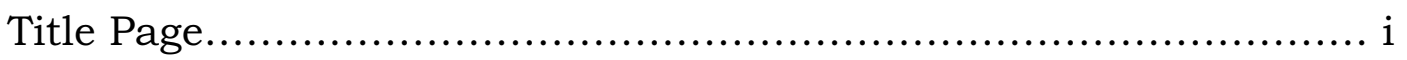

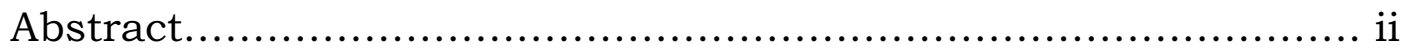

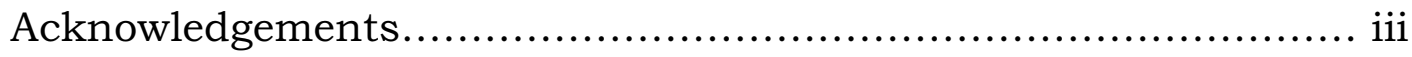

List of tables..........................................................

List of figures......................................................... vi

Chapter 1

Introduction............................................................. 1

Chapter 2

Seed germination of Fragaria x ananassa cv.'Sweetheart' ............. 8

Chapter 3

Plug production study with Fragaria x ananassa cv.'Fresca' .........12

Chapter 4

Nutriculture study of Fragaria x ananassa cv. 'Fresca' in coal bottom ash and rockwool

Chapter 5

Nutriculture Fragaria $\mathrm{x}$ ananassa cultivar study with

a coal bottom ash or rockwool substrate.

Chapter 6

Color analysis of Fragaria $\mathrm{x}$ ananassa fruit

Chapter 7

Flavor analysis of Fragaria $\mathrm{x}$ ananassa fruit 48

Chapter 8

Conclusions and future research......................................62

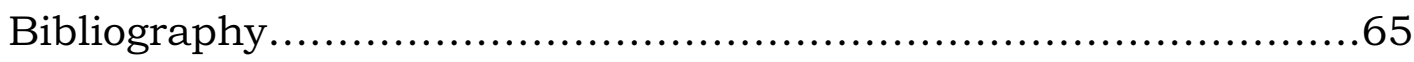

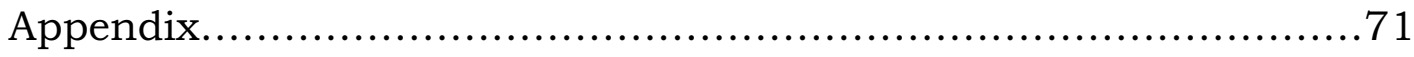

Curriculum Vitae................................................... 74 


\section{LIST OF TABLES}

Table 1-1: Recommended nutrient levels ............................... 7

Table 2-1: Germination of achenes 'Sweetheart' ......................... 11

Table 3-1: Number and rate of 'Fresca' achene germination ......... 16

Table 4-1: Plant growth parameters of 'Fresca' .......................... 28

Table 4-2: Flowering response of 'Fresca' ................................ 29

Table 4-3: Tissue nutrient content of 'Fresca' .......................... 30

Table 5-1: Plant growth parameters of different cultivars ............ 38

Table 5-2: Tissue nutrient content of different cultivars .............. 39

Table 6-1: External/Internal fruit color of 'Fresca' .................... 46

Table 6-2: External/Internal fruit color of different cultivars ....... 47

Table 7-1: GC peak areas for 'Fresca' fruit ............................ 57

Table 7-2: GC peak areas for different cultivars fruit ................. 58 


\section{LIST OF FIGURES}

Figure 3-1: Plug tray layout ............................................. 15

Figure 3-2: Germination graph of 'Fresca' achenes .................. 17

Figure 4-1: Nutriculture bench photo .................................... 26

Figure 4-2: Effluent collection tank photo .............................. 27

Figure 4-3: Tissue boron content for 'Fresca' ........................... 31

Figure 7-1: GC profiles of 'Fresca' fruit .................................. 59

Figure 7-2: GC profiles of 'Crimson King' fruit ........................ 60

Figure 7-3: GC profiles of 'Honeoye' fruit ............................... 61 


\section{CHAPTER 1 INTRODUCTION}

The cultivated strawberry of today's commercial market, Fragaria $\mathrm{x}$ ananassa (Duch.), is the result of over 200 years of breeding. The two species originally crossed in France were the Scarlet, Fragaria virginiana (Duch.), and the Chilean, Fragaria chileonsis (Duch.), brought from the Americas. Since that combination, "the crop with which we work is a highly prized and improved polyploid species hybrid, which is very responsive to environmental and cultural stimuli and manipulation. Thus we have been able to breed and select strawberry genotypes adapted to very different climates and for different purposes" (Galletta and Bringhurst, 1990).

The Fragaria are dicotyledonous angiosperm members of the Roseaceae distributed worldwide. The leaves are palmately compound with 3 to 5 leaflets. The plant habit, once classified as a hardy herbaceous rosette, is now classified as a compressed woody stem. Leaves are produced in a $2 / 5$ whorl. Fragaria axillary buds produce either flower stalks or stolons/runners. These stolons are vegetative reproduction structures with elongated nodes that upon contact with the soil produce roots and create daughter plants. The majority (50-90\%) of Fragaria roots are usually located in the top 6 inches of the soil. The Fragaria characteristically have superior ovaries that become the achenes, true (botanical) fruits, and fleshy conic shaped receptacles (the commercial fruit). Hereafter in this dissertation, both the achene and the receptacle together will be referred to as the fruit.

The fruit's fleshy receptacle may be divided into five tissue zones: 1) epidermis, polygonal stomata cells and long, pointed, thick walled hairs; 2) hypodermis, meristematic cells and no intercellular spaces; 3) cortex, true flesh of rounded cells with intercellular spaces; 4) bundle zone, xylem and 
phloem; and 5) pith, thin walled cells which may separate to form large central cavities (Szczesniak and Smith, 1969). During fruit growth and ripening there is a point when growth stops and the maturation process dominates the physiology of the fruit. After this point visual redness can be correlated with ripening and softening (Perez et. al., 1996). Fruit development has four identified stages: 1) white, 2) pink, 3) bright-red, and 4) dark red. Perez and colleagues (1996) identified maturation, ripening, to occur during late stage three and early stage four. As the receptacles ripen, the cell walls soften and the cell contents become liquefied allowing them to be easily damaged either physically or by pathogenic attack.

Fragaria are native to and produced around the world in both hemispheres. Cultivars and production systems vary by country and region. Europe has production areas "characterized by different latitudes, climatic conditions, cultivars, and cultural techniques" (Rosati, 1991). Europeans use intensive annual culture, plasti-culture, tunnel culture, open field, matted row, twin hill, or the hill row systems. Japan produces strawberries for the fresh market eight months of the year, December to June, using one of five different protocols (Oda, 1991). As of 1989, 89.6\% of the Japanese production was from "standard forcing culture". This is an annual cultivation system using homegrown runner plants held in raised nursery beds from July to August or September when they are planted into the production field with large plastic tunnels. The remaining $10.4 \%$ of Japanese cultivation is achieved with extra early forcing, cold-stored plants, open-field, or low tunnel protected culture (Oda, 1991). In the United States strawberries are grown in traditional open-field cultivation or modified field cultivation for multiple season harvests. These systems use differing row configurations, such as the traditional matted row, hill system, or the annual ribbon row. New protocols require the use of plastic mulch covered rows with annual cropping, i.e. plasti-culture, and micro-irrigation. Using this plasti-culture system in North Carolina, Fragaria x ananassa 
cv.'Chandler' can be spring-harvested seven to eight months after planting and for up to six weeks (Poling, 1991). All of these systems use either daughter plants or tissue cultured plants for field establishment.

Flowering and fruit set in Fragaria are as variable as the microclimates from which they originate. Most initiate flower buds in response to day-length. This response can be enhanced or subdued by temperature effects. The most temperature-sensitive group is the single cropping, June bearers. Whereas, the least temperature-sensitive, are the multiple cropping day neutral varieties. Those varieties classified as double cropping have an intermediate response to temperature.

The June-bearing varieties are short day-length responsive. In long-day conditions, as in summer, they initiate axillary or terminal vegetative buds. They initiate flower buds when exposed to the naturally occurring short day conditions in autumn (6-12 hours of daylight for 6-14 days) The formation of flower buds is also influenced by lower temperatures naturally associated with autumn or with a rise in elevation and the associated cooler climate. In the Mid-Atlantic outdoor setting, the June-bearing Fragaria will initiate flower buds in late summer or early fall, as day length shortens to 11 or 13 hours (Darrow, 1966). These flower primordia differentiate until the plant becomes winter dormant. Upon the increasing light and temperature during spring the flower clusters will enlarge and form the flowering trusses.

Day-neutral varieties initiate flower buds with either long-days or with night interruption lighting. "The older everbearers and the weak day-neutrals had similar growth habits and induced as many or more flowers as did the strong day-neutrals, but did not mature as many fruits as the strong dayneutrals... The very weak day-neutrals were large plants that behaved essentially like June-bearers" (Galletta and Bringhurst, 1990). 
This flowering response may also be categorized by the geographic region and genetic heritage from which the varieties are developed. "Northern varieties do not grow under the short days of winter even under a high temperature unless first given a rest period. Southern varieties may grow so vigorously so late in the season in the North that few flower buds are formed, and they are relatively unproductive." (Darrow, 1966)

The geographical region, site climatic conditions and soil nutritional status directly influence the production practices. Fragaria require a well draining substrate. Most production areas for field grown plants in the United States have sandy-loamy soils and/or have amended soils that are formed into raised hills or beds to allow for adequate drainage. In the Florida growing region, standard cultural practices include a pre-plant application of nitrogen and potassium fertilizer due to the high loss of nutrients in the sandy soils. Nitrogen and potassium added only through micro-irrigation increased plant size and average fruit weight but did not increase marketable fruit yields or number of marketable fruit per plant (Albregts et al., 1996).

With the majority (50-90\%) of Fragaria roots in the top 6" of the soil, cultural practices that maintain adequate moisture and nutrients in that locale enhance Fragaria growth and production. Mulching the rows with straw, various sawdusts, pine straw, or plastic have been used commercially and evaluated in scientific studies. All mulches studied help to conserve soil moisture and keep ripening fruit clean. Straw is also used as winter insulation when placed over the plants to be removed in the spring. Along with mulching, allowing plants to be planted no closer than five to six inches can increase yield.acre-1(May and Pritts, 1990).

Based on a survey of mineral nutrition literature for field grown strawberries, May and Pritts (1990) recommend foliar tissue analysis of the crop to have ranges listed in Table 1-1. The ranges in Table 1-1 are affected by when and 
at what physiological stage the plant is in when the samples are collected. Typically the most stable levels of foliar nutrients occur six weeks following fruit harvest (John et al., 1975).

Whether grown in the field (soil) or in the greenhouse (nutriculture) the goal is to produce a colorful, flavorful, and marketable fruit. As described by Nonnecke and Hayenga (1991), consumers ranked appearance most important, followed in order by cost, the fruit being locally grown, and finally the packaging when purchasing strawberries at an Iowa farmers' market. Appearance, being most important, includes red color intensity and distribution, fruit size and shape, and the freedom from decay and defects (Kader, 1991). In the Iowa survey, the consumers ranked color as the most important characteristic of the appearance followed in order by firmness, ripeness, overall quality, flavor, shape, and then shelf life (Nonnecke and Hayenga 1991).

Although consumers often base their initial purchasing on appearance, the decision to purchase the same product again depends on "flavor and other characteristics affecting fruit quality" (Galletta and Himelrick, 1990). Flavor is a complex combination of both taste and smell. For the strawberry, flavor quality has been linked to the sugar:acid ratio. As the fruit matures, the sugars increase and the acids decrease. Sugars may arise from imports, on site synthesis, or starch hydrolysis. They are mostly glucose and fructose, $83 \%$ in total ripe fruit sugars. The sugars are precursors to flavor compounds, such as furanones, and for color compounds, i.e. anthocyanins. The acids are thought to decrease through one or more of the following: the tricarboxylic acid cycle (TCA), respiratory metabolism, and/or by dilution as the fruit cells enlarge and hold more water.

The flavor is also associated closely with the aroma compounds that fruits release either intact or when macerated (chewed). Many studies have 
identified, through various methods, a total of 282 flavor compounds for Fragaria $\mathrm{x}$ ananassa and 91 flavor compounds for Fragaria vesca all of which are also found in the Fragaria $\mathrm{x}$ ananassa (Zabetakis and Holden, 1997). These studies employed isolation methods such as steam distillation, liquid-liquid extraction, liquid-solid extraction, and headspace trapping followed by concentration techniques to remove the solvent and leave only the compounds of interest which are often present in minute quantities. The compounds liberated during these methods are then identified through gas chromatography (GC), GC plus mass spectrometry (GCMS), nuclear magnetic resonance (NMR), or high pressure liquid chromatography (HPLC). The 282 compounds currently identified represent 11 chemical classes (acetals, acids, alcohols, aldehydes, esters, furans, ketones, lactones, terpenes, sulfur componds, and $\beta$-D-glyco-pyranosides). 
Table 1-1: Recommended nutrient levels for field grown strawberries as determined by foliar analysis, reported in either \% dry weight or parts per million.

\begin{tabular}{crrr}
\hline Nutrient & Foliar levels y & Foliar levels ${ }^{z}$ & Petiole levels $^{z}$ \\
\hline $\mathrm{N}$ & $2.0-2.8 \%$ & $2.71-30.2 \%$ & $0.77-0.83 \%$ \\
$\mathrm{P}$ & $0.25-0.4 \%$ & $0.287-0.293 \%$ & $0.145-0.16 \%$ \\
$\mathrm{~K}$ & $1.5-2.5 \%$ & $1.66-1.86 \%$ & $2.83-2.94 \%$ \\
$\mathrm{Ca}$ & $0.7-1.7 \%$ & $0.94-1.00 \%$ & $1.10-1.14 \%$ \\
$\mathrm{Mg}$ & $0.2-0.5 \%$ & $0.251-0.30 \%$ & $0.213-0.255 \%$ \\
$\mathrm{SO}_{4}$ & $>0.1 \%$ & $0.13 \%$ & $0.04-0.05 \%$ \\
$\mathrm{Fe}$ & $75-250 \mathrm{ppm}$ & $130-144 \mathrm{ppm}$ & $35.7-45.8 \mathrm{ppm}$ \\
$\mathrm{Mn}$ & $50-200 \mathrm{ppm}$ & $136-199 \mathrm{ppm}$ & $65.3-82.0 \mathrm{ppm}$ \\
$\mathrm{Zn}$ & $20-50 \mathrm{ppm}$ & $21.9-23.9 \mathrm{ppm}$ & $15.9-18.2 \mathrm{ppm}$ \\
$\mathrm{Cu}$ & $<20 \mathrm{ppm}$ & $8.1-8.8 \mathrm{ppm}$ & $4.6-4.8 \mathrm{ppm}$ \\
$\mathrm{B}$ & $30-90 \mathrm{ppm}$ & $33.5-40.2 \mathrm{ppm}$ & \\
$\mathrm{Mo}$ & $<1 \mathrm{ppm}$ & & \\
$\mathrm{Na}$ & & $28.2-31.7 \mathrm{ppm}$ & $44.3-49.6 \mathrm{ppm}$ \\
\hline
\end{tabular}

Y May and Pritts, 1990.

z John, et al., 1975 


\section{CHAPTER 2 \\ SEED GERMINATION OF \\ FRAGARIA X ANANASSA CV. 'SWEETHEART'}

\section{LITERATURE REVIEW}

Except for breeding programs, production of strawberries from seed is of small importance in the world wide commercial production scheme. The seed companies currently offer between one to three varieties of strawberry seed. These are aimed mostly at the high-end retail sales of specialty products for the homeowner. The European company, ABZ Aardneien uit zaad B.V. of Bovenkarspel, Holland, has recently released F-1 hybrid strawberries to be grown from seed for fruit production in both greenhouse and field systems.

Seed germination may be with either fresh seed that is not permitted to dry after removal from the receptacle and before sowing or dried seed. To use dried seed pre-treatments are recommended. Several studies have been conducted to evaluate treatments (chemical, photoperiod, and temperature) which would enhance normally low and variable achene germination percentages, rates, and synchrony (Bringhurst and Voth, 1957; Iyer et al., 1979; Nakamura, 1972; Scott and Draper, 1967; Scott and Ink, 1948; Thompson, 1969; and Wilson et al., 1973). In 1992, Miller et al. reported seed enhancement treatments that utilized tissue culture techniques for increasing the germination of progeny for genotype development in breeding programs. They identified two treatments, puncturing the endocarp near the hilum region and cutting the achene across the embryo axis, both increased seed germination rate. However, with $70 \%$ germinated at one week and a gradual increase to $90 \%$ in 6 weeks the cutting treatment was the most effective. Post germination losses in the Miller et al. study occurred in vitro (25\%), the mist bed (14\%), greenhouse acclimation (4\%), and the field (1\%) producing a 56\% 
survival rate to produce mature field grown plants and a total time to field transplant of 3.5 months for the cut achene treatment.

OBJECTIVE: To investigate current seed coat treatments for germination of commercially available Fragaria x ananassa achenes.

\section{MATERIALS AND METHODS}

Commercially available Fragaria x ananassa cv. 'Sweetheart' seeds were purchased from Vaughns Seed Co. Inc. (Downers Grove, IL). Upon arrival (June 1995), the seeds were held at 2C (45F) until August 1995. Seed treatments, as described by Miller et al. (1992), were applied to determine optimal germination procedures for this Fragaria variety developed for bedding plant production. The work area was sterilized with $10 \%$ chlorox $(0.5 \%$ final $\mathrm{NaOCl})$ for 10 minutes then rinsed with deionized water. All utensils (pin, tweezers, and razor blade) were flame sterilized. The seeds were surface sterilized for 10 minutes with $10 \%$ chlorox solution and rinsed with running de-ionized water for 2 minutes. Five treatments to be evaluated consisted of: 1) punctured hilum, 2) achene coat razor cut, 3) achene coat rubbed 4 times by hand with 320 extra fine sand paper, 4) achene coat rubbed 8 times by hand with 320 extra fine sandpaper ( $3 \& 4$ were substituted for the mechanical scarification described in Miller, et al. 1992), and 5) untreated (control). Five achenes from each of the five seed coat treatments were placed in individual petri dishes containing 2 layers of sterile gauze pads soaked with de-ionized water. Four petri dishes of each treatment were placed on $20 \mathrm{C}(68 \mathrm{~F}$ average, $74 \mathrm{~F}$ high to $64 \mathrm{~F}$ low) and four on $24 \mathrm{C}$ (76F average, $84 \mathrm{~F}$ high to $72 \mathrm{~F}$ low) propagation mats (Olson Products, Medina, $\mathrm{OH}$ ) with fluorescent lights $50 \mathrm{~cm}$ above the petri dishes, lighted for 24 hours at $100 \mu \mathrm{mol} \cdot \mathrm{m}^{-1} \cdot \mathrm{s}^{-1}$ Photosynthetically Active Radiation (PAR). Moisture levels were maintained with hand applications of de-ionized water. 
Minimum/maximum temperatures and number of germinated achenes, determined with the emergence of the radicle, were recorded daily.

\section{RESULTS}

Cutting the achenes caused germination to occur more rapidly (Table 2-

1) with only 10 days to germination for that treatment compared to 20 days for the control or the $4 \mathrm{x}$ or $8 \mathrm{x}$ scarified achenes. Seeds subjected to the puncture (pin) treatment had not germinated by the $20^{\text {th }}$ day. However, after 20 days all treatments, except the punctured achenes, exhibited equal or superior germination numbers compared to the cut treatment.

\section{DISCUSSION}

Similar to Miller et al. (1992) some pre-germination treatments of Fragaria $\mathrm{x}$ ananassa cv 'Sweetheart' caused both increased rate of germination and percentage of achenes germinated. Unlike that study, this study found that puncturing the achene in the hilum did not enhance germination, but rather diminished it, with no achenes germinated by day 20. The hilum is the point of attachment to the receptacle. And, although care was taken, it is possible that the embryo was damaged during the actual puncturing procedure, which would account for the lack of germination for this treatment. While the cut treatment decreased the time to germination, the scarification with sandpaper required less handling of individual achenes and exhibited high germination rates by day 20 for this commercially available cultivar. 
Table 2-1: Germination for achenes of Fragaria $\mathrm{x}$ ananassa cv 'Sweetheart' in response to cutting, puncturing or scarification and germination temperature. Values are mean germination of achenes with 10 seed for each of 4 replications per treatment.

\begin{tabular}{|c|c|c|c|c|}
\hline \multirow[b]{2}{*}{ Treatment } & \multicolumn{2}{|c|}{ Day 10} & \multicolumn{2}{|c|}{ Day 20} \\
\hline & $20 \mathrm{C}$ & $24 \mathrm{C}$ & $20 \mathrm{C}$ & $24 \mathrm{C}$ \\
\hline Untreated (control) & 0.00 & 0.00 & 2.25 & 1.75 \\
\hline Cut & 2.25 & 1.25 & 2.25 & 1.25 \\
\hline Pin & 0.00 & 0.00 & 0.00 & 0.00 \\
\hline Scarification $(4 \mathrm{x})$ & 0.00 & 0.00 & 3.25 & 1.50 \\
\hline Scarification $(8 \mathrm{x})$ & 0.00 & 0.00 & 3.25 & 3.00 \\
\hline
\end{tabular}




\section{CHAPTER 3 \\ PLUG PRODUCTION STUDY \\ WITH FRAGARIA X ANANASSA CV. 'FRESCA'}

\section{LITERATURE REVIEW}

Plug production of bedding plants from seed has increased rapidly in the last 20 years since plugs were first commercially used in the 1970's. "For high volume plug buyers, price, not selection, is the driving force. The increasing number of large growers using automatic transplanters also drives a demand for more uniform plugs and higher counts of usable plugs." (Beytes, 1997). With the large variety of plants produced from seed by plug growers, maintaining and guaranteeing quality for small quantity, specialty crops can become cost prohibitive. Usually plug trays are produced within a six to nine week (1.5 to 2 months) time period, which includes detailed attention of the grower through the four stages of plug production including the patching of trays to ensure the delivery of $100 \%$ plug tray usability (Beytes, 1997). At 14 weeks (3.5 months) production time from seed, strawberry plants fall outside the normal period for large scale plug producers.

OBJECTIVE: Using a commercial variety, identify the time required to reach $50 \%$ and $90 \%$ germination for four different plug substrates in the production of Fragaria plugs for transplants.

\section{MATERIALS AND METHODS}

Four 288 plug trays were filled with one of four substrates, Sunshine plug mix (Brighton By-products, New Brighton, PA), Rockwool (Hummertt International, Earth City, MO), Rockwool plus 10\% Ft. Martin coal bottom ash (CBA) (Ft. Martin Power Plant, WV), or Grodan Orchid Greenmix (Grodania, Milton, ON, Canada). Fragaria x ananassa cv. 'Fresca' achenes were purchased from Park Seed Co. Inc. (Greenwood, 
SC). Requiring light for germination, one achene per plug cell was seeded on top of the substrates. Each plug tray was separated into four equal sections and placed randomly into separate support trays (Figure 3-1). The trays were placed in the lab on shelves $50 \mathrm{~cm}$ beneath fluorescent lights. The trays were lighted for 24 hours at $100 \mu \mathrm{mol} \cdot \mathrm{m}^{-1} \cdot \mathrm{s}^{-1} \mathrm{PAR}$. The temperature in the lab averaged $26 \mathrm{C}(79 \mathrm{~F})$ due to climate controls outside the lab which were set for the building and not the room. The number of achenes germinated was recorded daily.

\section{RESULTS}

Sunshine plug mix and Orchid Greenmix had higher germination rates and number of achenes germinated throughout the three week study period compared to the rockwool or rockwool plus coal bottom ash media (Table 3-2). Achenes in Sunshine plug mix and Orchid Greenmix germinated $63.5 \%$ and $61.5 \%$ respectively by day 21 , while the rockwool and rockwool plus coal bottom ash germinated $47.2 \%$ and $38.2 \%$, respectively (Figure 3-2 ).

\section{DISCUSSION}

For the plug grower, the evaluation of the Fragaria $\mathrm{x}$ ananassa cv. 'Fresca' in plug tray media found that Sunshine plug mix and Grodan Orchid Greenmix supported germination of achenes in a 3 week period, 63.5 and $61.5 \%$ of total seeded respectively. These rates were reached although the temperature averaged $26 \mathrm{C}(79 \mathrm{~F})$ due to the internal whole facility temperature settings. Fragaria x ananassa are cool germinating. If the temperature could have been reduced to a lower level (optimum range being $20-22 \mathrm{C}, 65-68 \mathrm{~F}$ ), it might have enhanced germination further for all media tested. The reduced germination of achenes with the rockwool and rockwool $+10 \%$ Ft. Martin coal bottom ash may be associated with a nutrient charge or moisture difference of these media 
compared to the commercially available substrates for plug production. Further detailed studies are needed for these media in plugs, similar to the research conducted by Biernbaum and Fonteno (1996) into the micro environment of the plug tray. It might have been possible to increase the number of germinated achenes by increasing the time. However, since plug growers would like to produce quality plugs in the shortest period possible, a specialty crop like Fragaria, with an optimum germination temperature of $20 \mathrm{C}(68 \mathrm{~F})$, could also benefit from reduced temperature in the germination chamber for stage 1 and stage 2 of plug growth. Growers should also consider the nutrient availability in the plug media, looking for those media with characteristics similar to the Sunshine plug mix and the Grodan Orchid Greenmix. The growers should also over sow to provide adequate replacement plugs for tray patching to ensure $100 \%$ plug usability to the purchaser. 
Figure 3-1: Plug tray layout for achene production analysis of Fragaria x ananassa cv. 'Fresca'

\begin{tabular}{|l|l|l|l|}
\hline Tray 1 & Tray 2 & Tray 3 & Tray 4 \\
\hline
\end{tabular}

\begin{tabular}{|c|c|c|c|}
\hline D & B & C & A \\
\hline B & C & A & D \\
\hline C & A & D & B \\
\hline A & D & B & C \\
\hline
\end{tabular}
$\mathrm{A}=$ Sunshine plug mix
$\mathrm{B}=$ Rockwool
$\mathrm{C}=$ Rockwool plus $10 \% \mathrm{Ft}$. Martin coal bottom ash
$\mathrm{D}=$ Grodan Orchid Greenmix 
Table 3-1: Average number and rate of Fragaria x ananassa cv. 'Fresca' achenes germinated in a three week period in 4 - 72 cell sections of \#288 plug trays filled with Sunshine plug mix, Rockwool, Rockwool $+10 \%$ Ft. Martin coal bottom ash (RW + CBA) or Grodan Orchid Greenmix.

\begin{tabular}{|c|c|c|c|c|c|c|c|c|}
\hline \multirow[b]{2}{*}{ Day } & \multicolumn{8}{|c|}{ SUBSTRATE } \\
\hline & \multicolumn{2}{|c|}{ Sunshine } & \multicolumn{2}{|c|}{ Rockwool } & $\begin{array}{l}\text { RW + C } \\
\text { \#germ }\end{array}$ & $\begin{array}{l}\text { BA } \\
\text { Rate }\end{array}$ & Greenmix & $\begin{array}{l}\text { Rix } \\
\text { Rate }\end{array}$ \\
\hline & $10 \%=$ & $4.58 y$ & & & & & $10 \%=$ & 4.43 \\
\hline 6 & 6.00 & 1.00 & 0.75 & 0.13 & 0.25 & 0.04 & 6.00 & 1.00 \\
\hline 7 & $\begin{array}{l}15.75 \\
50 \%=\end{array}$ & $\begin{array}{r}2.86 \\
22.88\end{array}$ & $\begin{array}{l}1.50 \\
10 \%=\end{array}$ & $\begin{array}{c}0.21 \\
3.40\end{array}$ & $\begin{array}{l}1.50 \\
10 \%=\end{array}$ & $\begin{array}{l}0.21 \\
2.75\end{array}$ & 11.00 & 1.57 \\
\hline 8 & 24.75 & 3.09 & 4.00 & 0.50 & 3.25 & 0.41 & $\begin{array}{l}18.00 \\
50 \%=2\end{array}$ & $\begin{array}{r}2.25 \\
22.13\end{array}$ \\
\hline 9 & 26.00 & 2.89 & 6.25 & 0.69 & 5.25 & 0.58 & 22.75 & 2.53 \\
\hline 10 & 29.25 & 2.93 & 8.25 & 0.83 & 6.50 & 0.65 & 27.75 & 2.78 \\
\hline 11 & 32.75 & 2.98 & 10.50 & 0.96 & 8.25 & 0.75 & 30.50 & 2.77 \\
\hline 12 & 35.25 & 2.94 & 12.75 & 1.06 & 9.50 & 0.79 & 32.50 & 2.71 \\
\hline 13 & 36.25 & 2.79 & 16.00 & 1.23 & \begin{tabular}{|l}
13.75 \\
$50 \%$
\end{tabular} & 1.06 & 33.75 & 2.60 \\
\hline 14 & 38.25 & 2.73 & $\begin{array}{l}17.00 \\
50 \%\end{array}$ & 1.21 & 15.75 & 1.13 & 36.00 & 2.57 \\
\hline 15 & $\begin{array}{l}39.00 \\
90 \%=\end{array}$ & $\begin{array}{r}2.60 \\
41.18\end{array}$ & 19.75 & 1.32 & 18.25 & 1.22 & 36.50 & 2.43 \\
\hline 16 & 41.25 & 2.58 & 23.00 & 1.44 & 21.50 & 1.34 & 37.75 & 2.36 \\
\hline 17 & 41.25 & 2.43 & 23.75 & 1.40 & 22.25 & 1.31 & \begin{tabular}{|r|}
39.25 \\
$90 \%$ \\
39.8
\end{tabular} & $\begin{array}{l}2.31 \\
= \\
3\end{array}$ \\
\hline 18 & 44.25 & 2.46 & $\begin{array}{r}27.00 \\
90 \% \\
30 .\end{array}$ & $\begin{array}{l}1.50 \\
= \\
50\end{array}$ & $\begin{array}{l}23.75 \\
90 \%=\end{array}$ & $\begin{array}{r}1.32 \\
24.75\end{array}$ & 41.00 & 2.28 \\
\hline $\begin{array}{l}19 \\
20\end{array}$ & $\begin{array}{l}44.50 \\
45.75\end{array}$ & $\begin{array}{l}2.34 \\
2.29\end{array}$ & $\begin{array}{l}30.75 \\
34.00\end{array}$ & $\begin{array}{l}1.62 \\
1.70\end{array}$ & $\begin{array}{l}27.00 \\
27.50\end{array}$ & $\begin{array}{l}1.42 \\
1.38\end{array}$ & $\begin{array}{l}42.25 \\
44.25\end{array}$ & $\begin{array}{l}2.22 \\
2.21\end{array}$ \\
\hline $\begin{array}{l}\text { tal of } \\
88 \text { plugs } \\
\text { nal \% x }\end{array}$ & $\begin{array}{l}183 \\
63.5\end{array}$ & & $\begin{array}{l}136 \\
47.2\end{array}$ & & $\begin{array}{l}110 \\
38.2\end{array}$ & & $\begin{array}{l}177 \\
61.5\end{array}$ & \\
\hline
\end{tabular}


Figure 3-2: The total number out of 288 plugs of Fragaria x ananassa cv. 'Fresca achenes germinated over a 20 day period of time in Sunshine plug mix, Rockwool, Rockwool $+10 \%$ Ft. Martin coal bottom ash (CBA), or Orchid Greenmix.

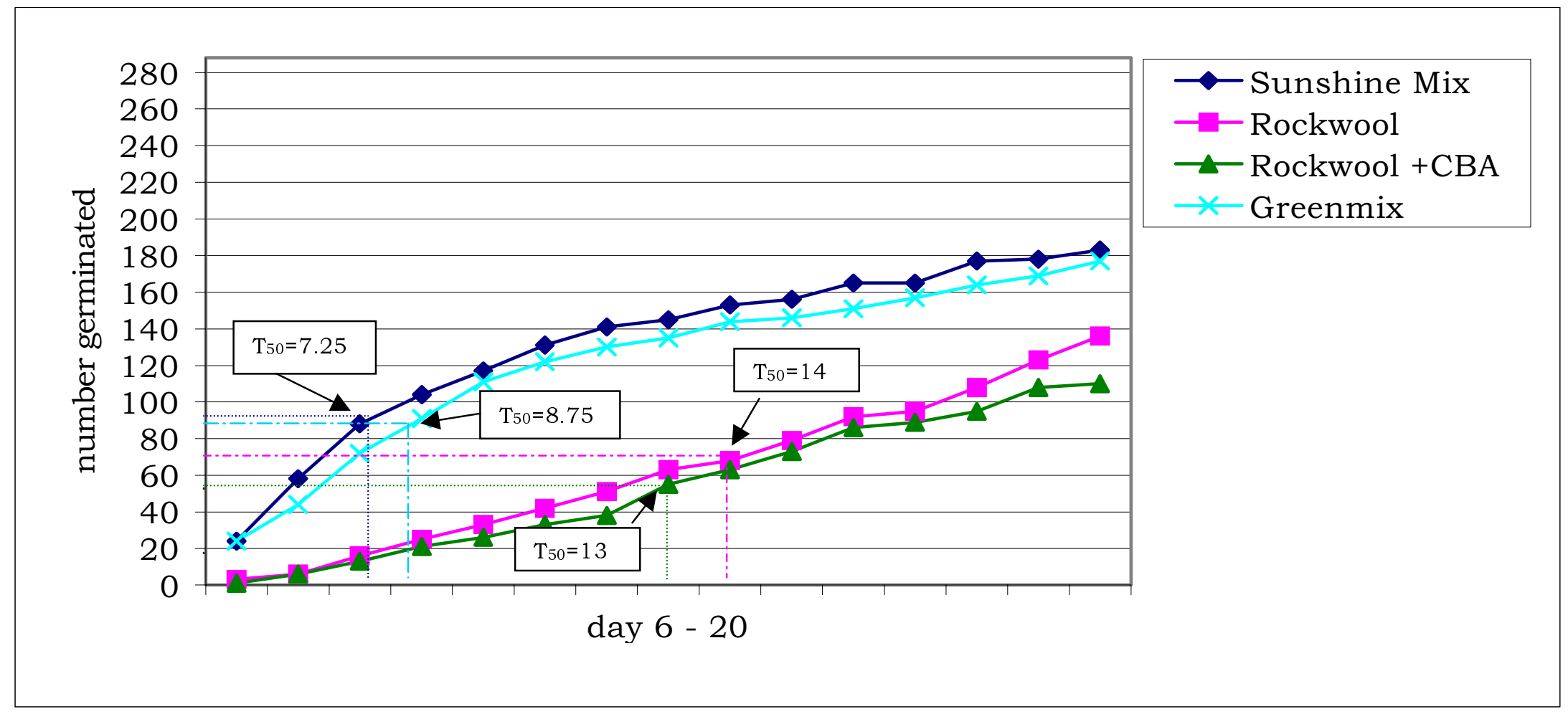

$\mathrm{T}_{50}=$ days to $50 \%$ germination 


\section{CHAPTER 4}

\section{NUTRICULTURE STUDY OF FRAGARIA X ANANASSA CV. 'FRESCA' IN COAL BOTTOM ASH AND ROCKWOOL}

\section{LITERATURE REVIEW}

Whether strawberries are grown in the field or in the greenhouse, Fragaria require a well draining substrate. Most production areas for field grown plants in the United States have sandy-loamy soils and/or have amended soils that are formed into raised hills or beds to allow for adequate drainage. These soils and field practices are influenced greatly by geographical location, climate and nutritional supplementation requirements. In the Florida growing region, standard cultural practices include a pre-plant application of nitrogen and potassium fertilizer due to the high loss of nutrients in the sandy soils. Albregts et al. (1996) found that nitrogen and potassium added only through micro-irrigation increased plant size and average fruit weight but did not increase marketable fruit yields or number of marketable fruit per plant.

For greenhouse production of strawberries, soil-less substrates are recommended. Commonly used substrates include traditional greenhouse peat based mixes and standard hydroponic or nutriculture substrates. The nutriculture substrate, rockwool, has proven useful in growing greenhouse crops whose end product is sold separate from the plant such as cut roses (Harless, 1994), tomatoes (Gritt, 1999; Carpenter, 1985), cucumbers, lettuce (Carpenter, 1985), and strawberries (Walker, 1996; Hunter and Morgan, 1989). Rockwool has also been used extensively as the substrate in research comparing fertilizers or growing conditions (Awang et al., 1993; Awang and Atherton, 1994; Hunter and Morgan, 1989). The use of rockwool allows growers to manipulate nutrient solutions to meet the crops requirements without the buffering encountered when using peat based mixes. At the University College Dublin, Hunter and Morgan (1989) found that 
strawberries in rockwool produced high quality fruit crops regardless of nutrient levels in August during the first season. However, after over wintering, the spring crop produced more fruit in the lower nutrient concentration. In 1985, it was reported by Morgan that under a nutrient film technique (NFT) production system, it is possible to produce 10 tons acre $^{-1}$ of strawberry fruit four times a year. By utilizing a nutriculture system in the greenhouse the grower can control the plant environment for timing nutrient supplements, light requirements, temperature, humidity, and atmosphere to produce ideal conditions for production of strawberry fruit.

Other nutriculture substrates include sand, perlite, fired clay products, and gravel. Since the late 1970's investigations into the use of an electric industry by-product, coal bottom ash (CBA), as a nutriculture substrate have been conducted at West Virginia University for cut crops of roses (Butler and Bearce, 1995) and marigolds (Woodard et al., 1993; Cluskey, 1989). Greenhouse chrysanthemums (pot mums) produced in a closed loop nutriculture system exhibited higher leaf tissue content for potassium and manganese but lower copper when grown in aged CBA than in fresh CBA (Bearce et al., 1993b). This is in opposition to the media (water extracts) results reported by Neal and Wagner (1983) which indicated fresh CBA was higher in potassium, manganese and 12 other elements compared to aged CBA indicating that there should be higher amounts of these elements available for plant uptake in the substrate solution. Roses grown in media containing CBA exhibited lower levels of tissue manganese and copper than the non-CBA media. However, the roses showed increased tissue content for boron when grown in media with CBA (Butler and Bearce, 1995)

Based on a survey of mineral nutrition literature for field grown strawberries May and Pritts (1990) recommend foliar tissue analysis of the crop to have ranges listed in Table 1-1. The ranges in Table 1-1 are affected by when and 
at what physiological stage the plant is in when the samples are collected. The most stable levels occurring in the six weeks following harvest (John et al., 1975).

OBJECTIVE: To evaluate growth parameters and nutrient uptake for Fragaria $\mathrm{x}$ ananassa cv.'Fresca' in response to root media (coal bottom ash and rockwool) and nutrient strength (full or half strength solution).

\section{MATERIALS AND METHODS}

STUDY 1 - RECIRCULATING NUTRICULTURE

Commercially available Fragaria x ananassa cv. 'Fresca' (Park Seed Co. Inc.

Greenwood, SC) seeds were placed randomly in petri dishes with 2 layers of sterile gauze kept moist with distilled water in the lab, April 1996. The dishes were placed $50 \mathrm{~cm}$ below fluorescent lights, 24 hours at $100 \mu \mathrm{mol} \cdot \mathrm{m}^{-1} \cdot \mathrm{s}^{-1}$ PAR. Upon germination, radicle and 2 cotyledon leaves visible, the seeds were placed on sterile cellulose plugs and maintained with Hydrosol (Appendix I) plus calcium nitrate at $1 / 10^{\text {th }}$ strength. After 3 months (July 10, 1996) the plugs/plants were transplanted into one of four substrates (rockwool - control, Albright CBA, Pleasants CBA, or Ft. Martin $\mathrm{CBA}$ ) and placed on the re-circulating nutriculture bench in an east-west glass greenhouse. All inflorescences were removed until the individual plants' leaf margins reached the pot edges. Forty-eight days after transplanting (August 28, 1996) the plants were measured edge to edge for 2 diameters (at right angle to each other), plant height measured as height of canopy above media surface, number of leaves, and total number of flowers (open and buds).

The re-circulating nutriculture bench was constructed of plywood sheets that angle from the center of the bench down at a $2 \%$ slope toward either side. Afixed to the plywood are individual saucers with drainage lines for each growing container (Figure 4-1). The drainage lines empty into collection pipes, which were designated for specific substrate - nutrient combinations 
and deliver the effluent from that combination into an individual solution stock tank. The stock tanks each contain a pump to re-circulate the nutrient solution through micro-irrigation tubes with drip emitters to the individual containers on the bench. A cover to eliminate light from the stock tanks was constructed to control algae growth in the solutions. The individual growing containers were 4" hanging basket containers (Hummertt International, Earth City, MO) lined with landscape fabric and filled with one of the four growing media. The rockwool (control) and the coal bottom ashes were placed in the containers to leave $1 / 2$ inch of space between the media surface and the rim of the container.

\section{STUDY 2 - FLOW THROUGH NUTRICULTURE}

Fragaria x ananassa cv. 'Fresca' seed were started in a 288 plug tray with sunshine Plug Mix in December 1996. These plugs were transplanted into one of four substrates in 5" nursery containers lined with landscape fabirc (February 1997): rockwool - control, Albright CBA, Pleasants CBA, or Fort Martin CBA in an east-west glass Greenhouse. All transplants were watered as needed for the first 7 days with steam distilled water and held under shade cloth. The containers were randomized and drip emitters for irrigation with either full or half strength Hydrosol plus calcium nitrate solution (Appendix I) were placed in the top of each container (Figure 4-2) in full sun. Two stock containers, 50 gal, were maintained with the nutient solutions. Drainage lines connected individual black plastic covered catch containers with one of eight effluent containers which collected the runoff for each of the eight substrate - nutrient level combinations (Figure 2-4). This was a flow through nutriculture system to guarantee the same nutrient content was delivered to each container with all irrigations. The date of the first flower, date of the first fruit, weight of the first fruit, and the total number of flowers (already fruit, open flower, and buds) were recorded for each container. More fruit would have been collected for analysis however, the 
plants were lost due to an infestation of mealy bugs which caused plant mortalities in all substrates.

All results were subjected to an analysis of variance for a general linear model with a randomized complete block factorial procedure on a statistical package for social sciences, SPSS (SPSS Inc., Chicago, IL). For factors with significant differences, the mean squares were separated with Duncan's New Multiple Range method.

\section{RESULTS}

\section{STUDY 1 - RECIRCULATING NUTRICULTURE}

Fragaria $\mathrm{x}$ ananassa cv. 'Fresca' plants exhibited increased plant area $\left(\mathrm{cm}^{2}\right)$ when grown in the Albright coal bottom ash (Table 4.1). The plants grown in the Ft. Martin coal bottom ash were intermediate between the Albright plants and the plants in either the Pleasants coal bottom ash or the rockwool control for plant area. For plant height $(\mathrm{cm})$, the plants grown in the Albright and Ft. Martin coal bottom ash were significantly taller than those grown in the Pleasants coal bottom ash or the rockwool control. The number of leaves per plant was significantly lower in the rockwool control than in any of the ash substrates (Table 4-1).

\section{STUDY 2 - FLOW THROUGH NUTRICULTURE}

There were no significant differences caused by any of the three coal bottom ashes or the strength of the nutrient solutions in days to flower, days to first fruit, first fruit weight, or total number of flowers when compared to the rockwool control (Table 4-2). Similar to study 1, there were no significant differences caused by the strength of the nutrient solutions in days to flower, days to first fruit, first fruit weight, or total number of flowers.

Tissue analysis of leaves and petioles analyzed for plant nutrient status indicated an interaction of substrate and nutrient solution strength and significant differences only for boron (Table 4-3). Separating the boron 
contents into substrates and nutrient solution strengths (Figure 4-3) the rockwool and the Ft. Martin coal bottom ash grown plants exhibited higher boron content for the full strength nutrient solution. The Albright coal bottom ash and Pleasants coal bottom ash grown plants had higher boron contents in the half strength nutrient solution. This higher boron content did not affect the plant growth.

For the other nutrients measured, there were no significant differences in the amounts for either substrate or nutrient solution strength. The Ft. Martin coal bottom ash grown plants, while not significantly so, were highest not only in boron but also in calcium, aluminum, manganese, and zinc. The rockwool grown plants were highest in magnesium, second to the Ft. Martin coal bottom ash grown plants for calcium and aluminum, and lowest in manganese and zinc. The Albright coal bottom ash grown plants were lowest in calcium, aluminum, and iron. The Pleasants coal bottom ash grown plants were highest of all plants in iron and lowest in boron and magnesium.

Comparing the nutrient contents of this study with the recommended levels of nutrients indicated that these plants were above the recommendations for calcium, boron, iron, and manganese. The levels were with in recommended amounts for magnesium and zinc. The amount of boron measured was 3-4 times higher than the upper recommended amount.

\section{DISCUSSION}

\section{STUDY 1 - RECIRCULATING NUTRICULTURE}

Although the rockwool grown plants were consistently in the lower range of all measured growth parameters, it is a commonly used root medium in nutriculture studies. Awang and colleagues (1993) found that increasing salinity to the root zone decreased fruit yield, increased dry matter percent, increased sugars and acids, decreased consumer color preference, and 
increased consumer preference for flavor in a rockwool nutriculture system. Awang and Atherton (1994) studied the effects of salinity, $\mathrm{NaCl}$, and shading on strawberry plant leaf water relations, photosynthesis, and nutrient composition. In addition, in 1995, Awang and Atherton expanded the rockwool salinity studies to evaluate leaf, crown, inflorescence initiations and fruit yield. In all three studies 'Rapella' strawberries exhibited reduced vegetative growth, as seen in the current study, and fruit yield with increased salinity. However, the quality of the fruit was enhanced with increased dry matter and the associated increase in sugars and acids concentration.

Marigolds (Tagetes erecta cv 'Inca Orange') and chrysanthemums (Dendranthema grandiflora cv 'Red Stingray') grown in closed-loop nutriculture system with rockwool substrate had significantly higher dry weights compared to coal bottom ash (Bearce et al., 1993a and 1993b). The chrysanthemums were taller when grown in rockwool and the marigolds exhibited higher fresh weights. In the marigold and mum studies, the rockwool was irrigated less frequently than the coal bottom ash due to the increased water holding capacity. The fact that in this study the rockwool and all three coal bottom ashes were irrigated on the same schedule may account for the reduced plant growth.

\section{STUDY 2 - FLOW THROUGH NUTRICULTURE}

Although there were no statistical differences in growth parameter measurements, with fruit weights of 9.1 to $10.2 \mathrm{~g}$, the coal bottom ashes produced a more commercially acceptable berry than the rockwool with a berry weight of $6.1 \mathrm{~g}$ (Table 3-4). The Iowa farmer's market consumer ranking of fruit appearance as their primary evaluation criteria may support this increased fruit size as desirable (Kader, 1991). There were no differences in the time required to either first flower or first fruit (Table 3-4). This would support research presented by Albregts and Howard (1985) indicating a link between the previous temperatures the plants are 
subjected to and the flower bud development and timing for strawberry crops. Since all of the plants in this study were subjected to the same temperature regime, it would logically follow that they should flower at similar times.

Researching the effects of calcium on post-harvest firmness, Makus and Morris (1989 and 1998) reported that pre-harvest calcium supplementation increased foliar calcium levels, but did not increase fruit calcium levels. Fruit characteristics were not influenced by these fertilization studies. They did report that fruit decay was consistently reduced. In the 1998 study, they reported that calcium was partitioned to the achenes in larger quantities than to the receptacle. This supports El Ghaouth and colleagues (1991) report that the achenes, not the receptacles, are a source of antifungal glucanohydrolases and indicates a possible link between calcium content of the achenes and the production of this antifungal compound. Although the fruit calcium content was not measured, the plants in this study showed above recommended levels of plant tissue calcium content, which could possibly influence achene calcium content. This would then affect glucanohydrolases and postharvest quality of the fruits. 
Figure 4-1: Nutriculture bench set-up for production of individual Fragaria $x$ ananassa cv. 'Fresca' plants with effluent collection tubes for individual pots and drip emitters for irrigation from the stock tanks in the background.

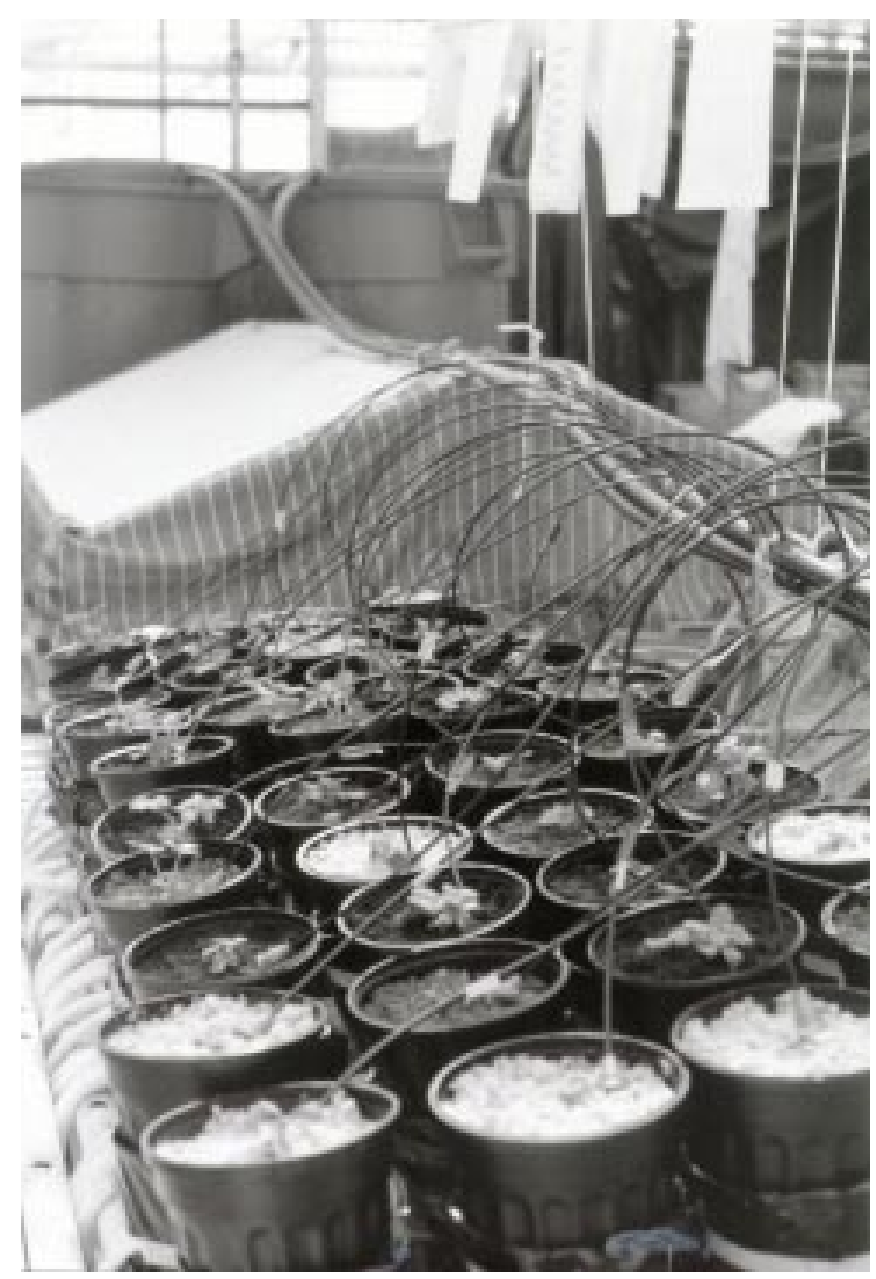


Figure 4-2: Drainage lines to collection tanks for each substrate - nutrient strength solution combination.

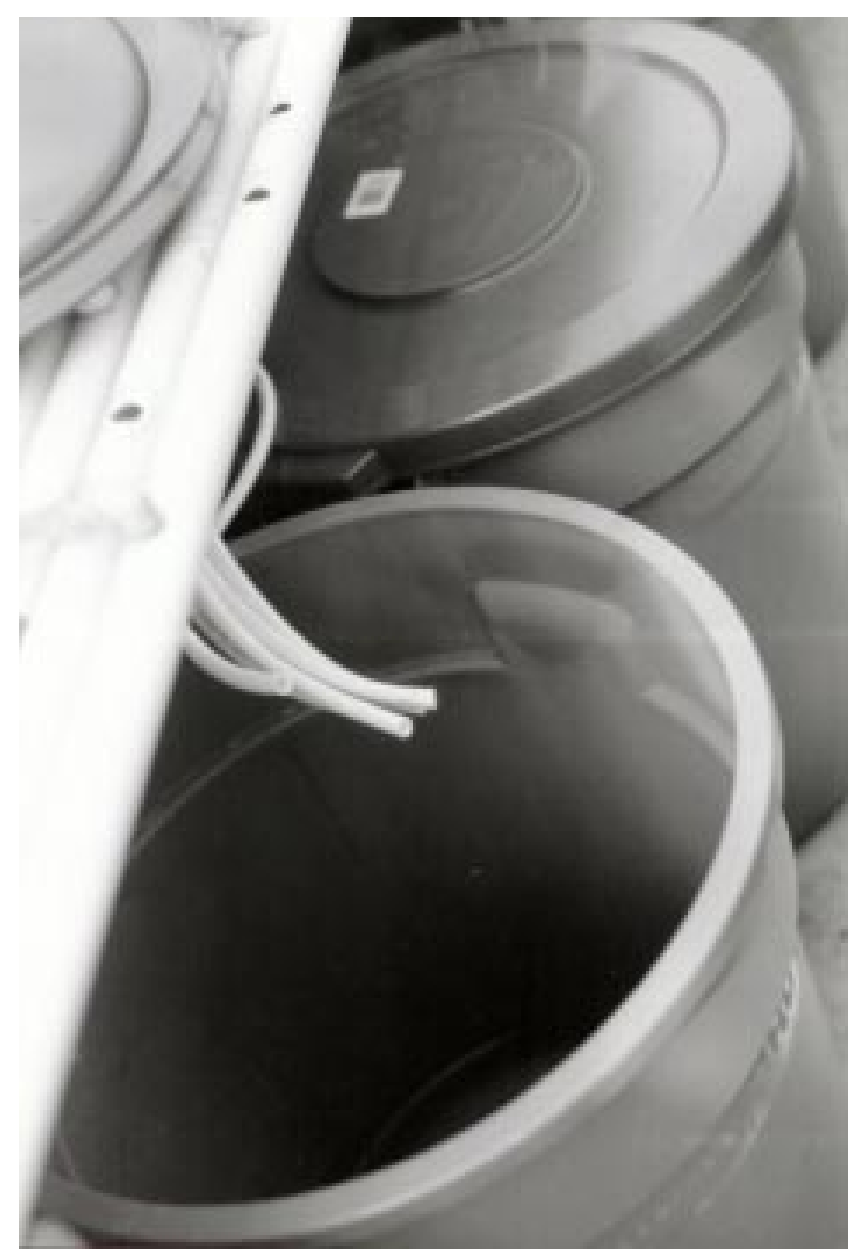


Table 4-1: Growth of Fragaria $\mathrm{x}$ ananassa cv 'Fresca' in response to root substrate and nutrient level in a nutriculture system.

\begin{tabular}{|c|c|c|c|c|}
\hline Substrates & $\begin{array}{c}\text { Plant area } \\
\left(\mathrm{cm}^{2}\right)^{z y}\end{array}$ & $\begin{array}{c}\text { Plant height } \\
(\mathrm{cm})^{\mathrm{y}}\end{array}$ & $\begin{array}{c}\text { \# of } \\
\text { leaves }\end{array}$ & $\begin{array}{c}\text { \# of } \\
\text { flowers }\end{array}$ \\
\hline Rockwool & $103.3^{b}$ & $5.6^{b}$ & $8.2^{b}$ & 0.5 \\
\hline Albright CBA & $203.5^{a}$ & $8.9^{a}$ & $12.9^{a}$ & 1.4 \\
\hline Pleasants CBA & $111.5^{b}$ & $6.2^{\mathrm{b}}$ & $10.6^{a b}$ & 0.3 \\
\hline Ft. Martin CBA & $160.1^{\mathrm{ab}}$ & $8.1^{\mathrm{a}}$ & $13.1^{a}$ & 0.4 \\
\hline Half strength nutrients & 132.2 & 7.4 & 11.0 & 0.8 \\
\hline Full strength nutrients & 161.1 & 7.2 & 11.8 & 0.5 \\
\hline \multicolumn{5}{|l|}{ Significancex } \\
\hline Substrate (sub) & $* *$ & $* *$ & $* *$ & NS \\
\hline Nutrient (nutr) & $\mathrm{Ns}$ & $\mathrm{Ns}$ & $\mathrm{Ns}$ & $\mathrm{Ns}$ \\
\hline Sub*Nutr & NS & NS & * & NS \\
\hline
\end{tabular}

$\mathbf{z}$ Plant area $=$ average of two diameters taken at right angles divided by 2 to give radius for $=\pi r^{2}$

y Separation of means by Duncan's New Multiple Range

$\mathbf{x}$ NS, ${ }^{*}, * *$, not significant, significant at the $\alpha=0.05$ level or significant at the $\alpha=0.01$ level, respectively 
Table 4-2: Flowering and fruiting response of Fragaria x ananassa cv 'Fresca' grown in rockwool (control), or Albright CBA, Pleasants CBA, or Ft. Martin CBA, at two nutrient levels.

\begin{tabular}{l|cccc}
\hline \hline & $\begin{array}{c}\text { Days to 1st } \\
\text { flower }\end{array}$ & $\begin{array}{c}\text { Days to 1st } \\
\text { fruit }\end{array}$ & $\begin{array}{c}\text { Weight of } \\
\text { 1st fruit }\end{array}$ & $\begin{array}{c}\text { Total } \\
\text { flowers }\end{array}$ \\
\hline Rockwool & 57.7 & 74.0 & 6.1 & 43.8 \\
Albright CBA & 55.8 & 76.5 & 10.2 & 55.9 \\
Pleasants CBA & 55.4 & 72.6 & 9.4 & 42.4 \\
Ft. Martin CBA & 55.7 & 75.2 & 9.1 & 55.0 \\
\hline Half strength nutrients & 58.5 & 74.5 & 8.1 & 56.2 \\
Full strength nutrients & 54.3 & 74.9 & 9.6 & 42.3 \\
\hline Significancez & & & & NS \\
\multicolumn{1}{|c|}{ Substrate (sub) } & NS & NS & NS & NS \\
Nutrient (nutr) & NS & NS & NS & NS \\
Sub*Nutr & NS & NS & NS & \\
\hline
\end{tabular}

${ }_{\mathrm{NS}},{ }^{*},{ }^{* *}$, not significant, significant at the $\alpha=0.05$ level or significant at the $\alpha=0.01$ level, respectively 
Table 4-3: Plant tissue nutrient analysis (mg. $\mathrm{kg}^{-1}$ dry weight) with, leaf and petiole, samples taken 6 weeks following fruit harvest of greenhouse grown Fragaria x ananassa cv 'Fresca'

\begin{tabular}{|c|c|c|c|c|c|c|c|}
\hline & $\mathbf{C a}$ & Mg & A1 & $\mathbf{B}^{z}$ & $\mathbf{F e}$ & Mn & $\mathbf{Z n}$ \\
\hline Rockwool & 20168.5 & 4719.8 & 173.85 & $348.60^{b}$ & 486.00 & 211.88 & 39.23 \\
\hline Albright CBA & 17822.8 & 3940.7 & 115.95 & $357.23 \mathrm{~b}$ & 433.58 & 263.48 & 40.28 \\
\hline Pleasants CBA & 18169.7 & 3859.1 & 169.80 & $341.25^{b}$ & 545.48 & 258.68 & 45.68 \\
\hline Ft. Martin CBA & 24321.9 & 4644.1 & 178.50 & $380.85^{a}$ & 497.48 & 328.20 & 46.43 \\
\hline Half strength & 21533.5 & 4585.9 & 157.01 & 354.83 & 458.55 & 235.09 & 46.88 \\
\hline Full strength & 18707.9 & 3996.9 & 162.04 & 359.14 & 522.71 & 296.03 & 38.93 \\
\hline \multicolumn{8}{|l|}{ Significancey } \\
\hline Substrate (sub) & NS & NS & NS & * & NS & NS & NS \\
\hline Nutrient (nutr) & NS & NS & NS & NS & NS & NS & NS \\
\hline Sub*Nutr & NS & NS & NS & ** & NS & NS & NS \\
\hline \multirow[t]{2}{*}{ Recommended levels $x$} & 7000 to & 2000 to & - & 30 to 90 & 75 to 250 & 50 to 200 & 20 to 50 \\
\hline & 17000 & 5000 & & & & & \\
\hline
\end{tabular}

$z$ mean separation by Duncan's multiple range at the $\alpha=0.05$ level

y $\mathrm{NS},{ }^{*}, * *$, not significant, significant at the $\alpha=0.01$ level, significant at the $\alpha=0.05$ level, respectively

x May and Pritts, 1990. 
Figure 4-3: Boron content for leaf and petiole nutrient analysis of Fragaria $\mathrm{x}$ ananassa cv. 'Fresca' grown in rockwool control or one of three coal bottom ashes (CBA) irrigated31with either a full strength or half strength hydrosol + calcium nitrate solution

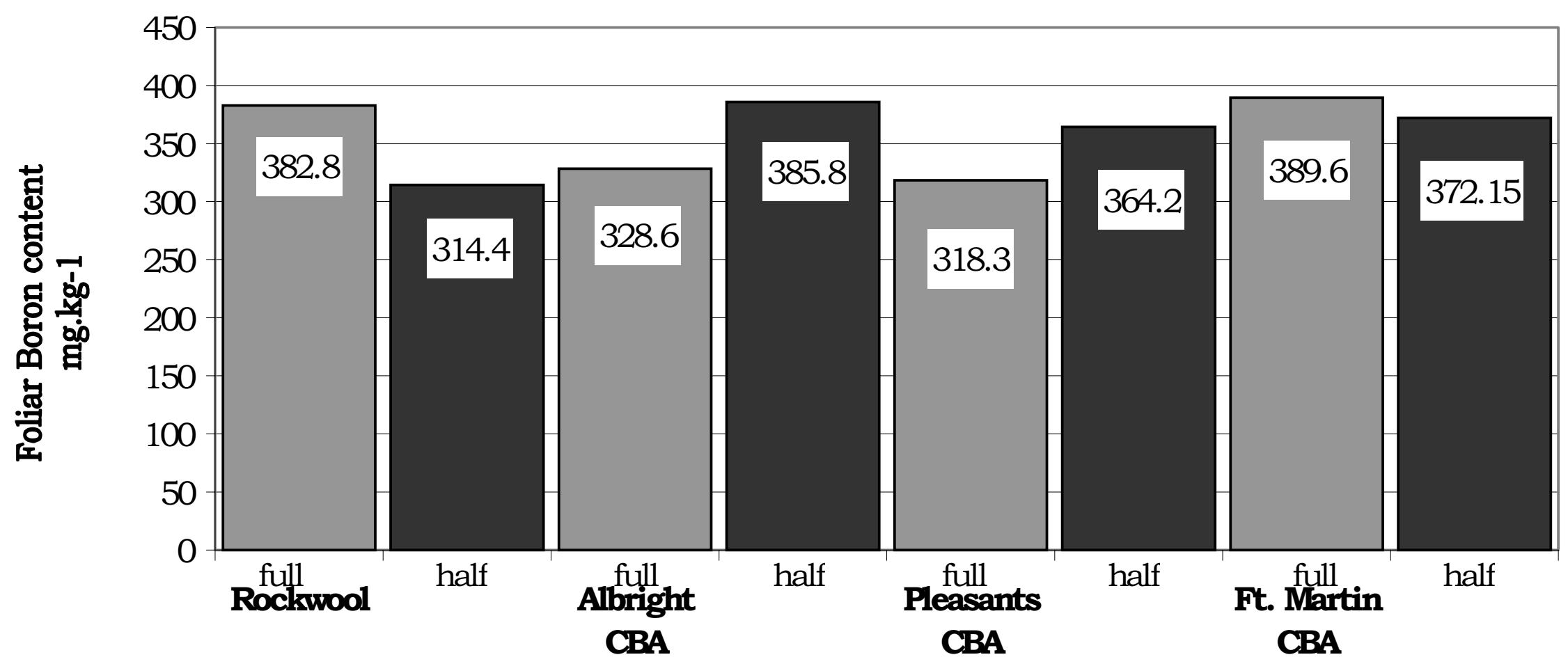




\section{CHAPTER 5}

\section{NUTRICULTURE FRAGARIA X ANANASSA CULTIVAR STUDY WITH A COAL BOTTOM ASH OR ROCKWOOL SUBSTRATE}

\section{LITERATURE REVIEW}

The strawberry varieties are highly diverse. These varieties are not only bred for growing region and market adaptation, but also for disease resistance, insect resistance, cold hardiness, heat tolerance, fruiting patterns and fruit characteristics. As new varieties are developed and released production patterns shift to utilized these varieties. In the northeastern US, 'Sunrise' and 'Earlidawn' have been replaced by 'Earliglow' due to its attractive and flavorful fruit in the early season (Galletta, 1989). The climatic conditions of this region also require the development of cultivars that are disease resistant to red stele root rot (Phytophthora fragariae), Verticillium wilt, powdery mildew (Spaerotheca macularis), leaf spot (Didymella fragariae), and leaf scorch (Diplocarpon earliana) (Chandler, 1991). It has long been known that "Northern varieties do not grow under the short days of winter even under a high temperature unless first given a rest period. Southern varieties may grow so vigorously so late in the season in the North that few flower buds are formed, and they are relatively unproductive." (Darrow, 1966)

Fruit characteristics of strawberries for 63 varieties were evaluated at the Ohio Agriculture Research and Development Center at Wooster in the late 1980's. These characteristics included firmness, color, acidity traits, and aroma traits. The results were then classified into clusters and compared against the decade of the introduction for that variety. The largest and firmest berries were of the most recently released varieties. Color reflected the area of development more than the decade of release. For instance, the southeast preferred berries with a more orange-red color than the darker berries of the northeast and northwest regions (Scheerens and Brenneman, 1991). Studies have also demonstrated cultivar differences for salt tolerance 
(Esensee et al., 1991; Awang and Atherton, 1994) and drought stress resistance (Archbold and Zhang, 1991). These studies indicate that plants with Fragaria chiloensis in the heritage survived salt and drought environments more readily.

In the previous study, Chapter 4, there were clear differences in the same cultivar, Fragaria x ananassa cv. 'Fresca', grown in either rockwool or one of three coal bottom ashes. The rockwool grown plants were smaller plants than those grown in coal bottom ash. The plants also indicated differing foliar nutrient levels in the different substrates.

OBJECTIVE: To assess the effect of root substrate on different cultivars of Fragaria $\mathrm{x}$ ananassa for growth, production and foliar nutrient status.

\section{MATERIALS AND METHODS}

Runner plants of commercially available Fragaria x ananassa cultivars were received May 1997 (Table 2-1), placed in the cooler and held at 5C (41F) until they were planted in five inch nursery containers into either rockwool (control) or Ft. Martin coal bottom ash, July 1997. The plants were watered in with tap water, placed under $30 \%$ shade cloth in an east-west glass house, and misted several times a day. After all were planted, they were drenched with $150 \mathrm{ml}$ per five inch nursery pot of the fungicide Benomyl, 44 $\mathrm{g} \cdot \mathrm{l}^{-1}$. After one week they were randomized on the bench and fertilized with full strength Hydrosol and calcium nitrate (Appendix I) solution. These plants were maintained throughout the study with fertilizer applied at all irrigations, with only an occasional tap water irrigation, by means of a flow through nutriculture system. The container medium $\mathrm{pH}$ was monitored with the pour-through method and maintained in the range of 6.0 to 7.0 by adjustment of the irrigation solution with concentrated sulfuric acid to lower the $\mathrm{pH}$. A stock container, 50 gal, was maintained with the fertilizer solution. 
The date of the first flower was recorded for each container. As the fruit reached full red, between stage 3 and stage 4 (Perez et al., 1996), they were harvested with cap and pedicle intact. Within 1 hour of harvest color measurements were taken with a Minolta tri-stimulus colorimeter (Minolta, Ramsey, NJ, USA).

Six weeks following final fruit harvest, the leaves and petioles were collected and measured for fresh weights, number of leaves, and leaf area (Li-3100 area meter, Licor Inc., Lincoln, Nebraska). These samples were then dried to a constant weight and dry weights were recorded. The dry material was ground with a Cyclotec 1093 Sample Mill (Tecator, Sweden). The ground material was sieved to pass through a 500mic, mesh number 35 ASTM E-11 sieve (Soiltest Inc., Evanston, IL, USA). Using $0.5 \mathrm{~g}$ of this material, microwave nitric acid digestion (CEM Corporation MDS 2000 microwave, Matthews, NC) was carried out (Appendix II). The resulting liquid samples were filtered through Whatman's 42 ashless filter paper. A 1 in 10 dilution was prepared with each sample and the elemental analysis was determined with a Plasma 400 ICP Spectrometer (Perkin-Elmer, Norwalk, CT).

All results were subjected to an analysis of variance for a general linear model with a randomized complete block factorial procedure on a statistical package for social sciences, SPSS (SPSS Inc., Chicago, IL). For factors with significant differences, the mean squares were separated with Duncan's New Multiple Range method.

\section{RESULTS}

Leaf area, leaf fresh weight and leaf dry weight of all cultivars in coal bottom ash were significantly lower than plants in the rockwool control (Table5-1). However, no cultivar effects on these growth parameters were seen. Plant crown and leaf numbers were not affected by substrate but were influenced 
by cultivar. Surecrop, Honeoye, and Ozark Beauty had more crowns per plant than Crimson King or Cardinal. Surecrop had more leaves per plant then either Crimson King or Cardinal.

For the commercially available cultivars used in this study the only element above recommended leaf tissue levels was boron (Table 5-2). Boron was consistently above $200 \mathrm{mg} \cdot \mathrm{kg}^{-1}$ dry weight for all tissue analyzed, except in the sample from the cv. 'Earliglow' which was only analyzed for plants grown in the rockwool control and which exhibited a level within the recommended range. This was considerably below the mean for boron across all cultivars in rockwool. The only other differences identified among the cultivars were for magnesium, manganese (both at the $\alpha=0.01$ level), and iron (at the $\alpha=0.05$ level).

\section{DISCUSSION}

Unlike the preliminary nutriculture study and the 'Fresca' substrate study, the evaluation of five different cultivars of Fragaria $\mathrm{x}$ ananassa showed Ft. Martin coal bottom ash grown plants to be significantly lower than the rockwool control when measured for leaf area, leaf fresh weight and leaf dry weight. This is in agreement with the Bearce et al. (1993 a \& b) reports that coal bottom ash decreased plant heights for chrysanthemums (Dendranthema grandiflora cv. 'Red Stingray') and decreased fresh weight for marigolds (Tagetes erecta cv. 'Inca Orange'). Coal bottom ash appears to adversely affect certain growth parameters while not affecting others in strawberry as well as chrysanthemums and marigolds.

The number of crowns per plant and the number of leaves although not affected by substrate, exhibited responses due to the cultivars. Cultivars exhibit a wide range of crown habits based on their genetic combination of parental characteristics. Production temperatures may also elicit cultivar 
specific responses. Leaf growth is optimum between $20-26 \mathrm{C}$ (68-79F). If a cultivar is bred for the northeast, it may respond to greenhouse conditions of increased temperature with the development of branch crowns more quickly than a cultivar bred for the southern regions. Geater and collegues (1997) reported that Fragaria viridis obtained maximum growth at 23C, while Fragaria chiloensis growth was maximized at 32C. They also reported that $35 \mathrm{C}$ in the root zone inhibited vegetative growth, runner number and runner plant development.

Strawberry roots are dependent on soil oxygen/air space. Any soil or medium which retains excess soil water around the root zone can cause rootlet death, delayed or immediate (Wilhelm and Nelson, 1970). Sandy loams are often considered the best mineral soil for strawberry production (Galletta and Bringhurst, 1990). The bulk density and pore space of coal bottom ash reported by Cluskey (1989) describe a root media that retains nutrients but also exhibits good internal drainage. This combination would support the use of coal bottom ash in a nutriculture system for strawberry growth. The reduced plant growth observed in this study combined with the media characteristics just presented would indicate a need to evaluate irrigation frequency as a possible reason for this observed reduction in plant growth. As concluded by the study of marigolds in a similar system, coal bottom ash required more frequent irrigation when compared against a rockwool control (Bearce et al., 1993 a) to provide adequate moisture to the crop and avoid drought stress.

The nutrient analysis of the cultivars indicates the uptake within recommended limits of most nutrients. Even though, in the 'Fresca' study (Chapter 4) most nutrients were accumulated above recommended levels in the same substrates. This conflict between the two studies may be linked to the heritage of the cultivars and the fact that the cultivars used in this study were bred for commercial field production. Reporting on fruit quality 
and its relationship with the decade and area of release Scheerens and Brenneman (1991) reported firmness values for the cultivars used in this study. They report that the 'Crimson King' and 'Honeoye' fruit are valued the same and having firmer berries, the 'Cardinal' and 'Surecrop' are equal and softer, and the 'Earliglow' is in between the two groups. Combine this with the Makus and Morris (1989 and 1998) reports that pre-harvest calcium supplementation increased foliar calcium levels, but did not increase fruit calcium levels, and that fruit characteristics were not influenced by these fertilization studies. These previous reports would not support the analysis in the current study of 'Crimson King' and 'Honeoye', described as having firm fruit, and having the highest foliar calcium levels. Also, the contrast of the 'Earliglow' reported as being medium in fruit firmness, when this study found that 'Earliglow' grown in rockwool had much lower foliar calcium level than the mean of fruit grown in rockwool across the cultivars for calcium. As in the 'Fresca' study (Chapter 4) boron was found in elevated levels for the foliar nutrient analysis. Unlike the 'Fresca' study, all other nutrients were within recommended levels, with the exceptions of 'Earliglow' in rockwool. The 'Cardinal' iron level was below the recommended, and the 'Annapolis' exhibited low zinc measurements 
Table 5-1: Plant growth parameters for five cultivars of Fragaria $\mathrm{x}$ ananassa grown in either rockwool or coal bottom ash nutriculture substrate. The plants were harvested six weeks after fruit harvest.

\begin{tabular}{|c|c|c|c|c|c|}
\hline & Leaf area $\left(\mathrm{cm}^{2}\right)$ & $\begin{array}{c}\text { Leaf fresh } \\
\text { weight }\end{array}$ & $\begin{array}{c}\text { Leaf dry } \\
\text { weight }\end{array}$ & \# of crowns ${ }^{z}$ & \# of leaves ${ }^{2}$ \\
\hline Crimson King & 1816.24 & 51.19 & 15.78 & $3.4^{\mathrm{b}}$ & $29.29^{c}$ \\
\hline Cardinal & 2077.16 & 59.39 & 20.63 & $3.4^{\mathrm{b}}$ & $36.93^{\mathrm{bc}}$ \\
\hline Surecrop & 2552.18 & 66.10 & 21.10 & $4.7^{a}$ & $54.00^{a}$ \\
\hline Honeoye & 2349.61 & 68.02 & 22.35 & $4.8^{a}$ & $47.43^{\mathrm{ab}}$ \\
\hline Ozark Beauty & 2431.73 & 67.31 & 20.79 & $4.9 \mathrm{a}$ & $46.57^{\mathrm{ab}}$ \\
\hline Coal Bottom Ash & 2047.68 & 56.45 & 18.08 & 4.2 & 41.94 \\
\hline Rockwool & 2443.09 & 68.35 & 22.17 & 4.3 & 43.74 \\
\hline \multicolumn{6}{|l|}{ Significancey } \\
\hline Cultivar (Cv) & NS & NS & NS & $* *$ & $* *$ \\
\hline Substrate (Sub) & * & * & * & NS & NS \\
\hline $\mathrm{Cv}^{*} \mathrm{Sub}$ & NS & NS & * & NS & NS \\
\hline
\end{tabular}

z Separation of means by Duncan's New Multiple Range

y NS, *, **, not significant, significant at the a=0.05 level or significant at the a=0.01 level, respectively 
Table 5-2: Plant tissue nutrient analysis (mg. $\mathrm{kg}^{-1}$ dry weight) with, leaf and petiole, samples taken 6 weeks following fruit harvest of greenhouse grown Fragaria x ananassa cultivars.

\begin{tabular}{|c|c|c|c|c|c|c|c|}
\hline & $\mathbf{C a}$ & $\mathbf{M g}^{\mathrm{z}}$ & $\mathbf{A 1}$ & $\mathbf{B}$ & $\mathbf{F e}^{z}$ & $\mathbf{M n}{ }^{z}$ & $\mathbf{Z n}$ \\
\hline Crimson King & 13560.6 & $4229.8^{a}$ & 58.95 & 308.03 & 146.93 & $90.23^{b}$ & 23.63 \\
\hline Cardinal & 12044.8 & $3584.8 \mathrm{a}$ & 62.33 & 284.85 & 68.63 & $101.25 \mathrm{ab}$ & 28.13 \\
\hline Surecrop & 13222.4 & $3273.1^{\mathrm{a}}$ & 71.40 & 287.48 & 147.53 & 145.58 a & 30.53 \\
\hline Honeoye & 13273.8 & $3473.8^{a}$ & 57.15 & 272.63 & 142.95 & $107.55 \mathrm{ab}$ & 22.50 \\
\hline Earliglow (RW only) & 4842.8 & $22.3^{b}$ & 52.20 & 55.20 & 55.80 & $24.75^{c}$ & 11.25 \\
\hline Annapolis (CBA only) & 12253.4 & 3707.9 a & 76.35 & 200.55 & 189.15 & $95.40^{b}$ & 15.75 \\
\hline Coal Bottom Ash (CBA) & 12351.2 & 3486.4 & 63.12 & 253.20 & 134.82 & 106.50 & 25371 \\
\hline Rockwool (RW) & 11908.6 & 3084.3 & 62.52 & 259.14 & 116.58 & 95.37 & 21.60 \\
\hline \multicolumn{8}{|l|}{ Significance ${ }^{y}$} \\
\hline Cultivar (Cv) & NS & ** & NS & NS & * & $* *$ & NS \\
\hline Substrate (Sub) & NS & NS & NS & NS & NS & NS & NS \\
\hline $\mathrm{Cv}^{*} \mathrm{Sub}$ & NS & NS & NS & NS & NS & NS & NS \\
\hline Recommended levels $\mathrm{x}$ & $\begin{array}{c}7000 \text { to } \\
17000\end{array}$ & $\begin{array}{c}2000 \text { to } \\
5000\end{array}$ & - & 30 to 90 & $\begin{array}{l}75 \text { to } \\
250\end{array}$ & 50 to 200 & $\begin{array}{c}20 \text { to } \\
50\end{array}$ \\
\hline
\end{tabular}

$z$ mean separation by Duncan's multiple range at the $\alpha=0.05$ level

y $\mathrm{NS},{ }^{*}, * *$, not significant, significant at the $\alpha=0.01$ level, significant at the $\alpha=0.05$ level, respectively

x May and Pritts, 1990. 


\section{CHAPTER 6 \\ COLOR ANALYSIS OF FRAGARIA X ANANASSA FRUIT}

\section{LITERATURE REVIEW}

Whether growing strawberries in the field (soil) or the greenhouse

(nutriculture) production of a colorful, flavorful, marketable fruit is the goal.

As described by Nonnecke and Hayenga (1991), consumers ranked

appearance most important, followed in order by cost, locally grown, and packaging when purchasing strawberries at an Iowa farmers' market. In this survey, the consumers ranked color as the most important characteristic of appearance followed in order by firmness, ripeness, overall quality, flavor, shape and then shelf life. Appearance includes red color intensity and distribution, fruit size and shape, and the freedom from decay and defects (Kader, 1991).

During fruit growth and ripening there is a point when growth stops and the maturation process dominates the physiology of the fruit. After this point visual redness can be correlated with ripening and softening (Perez et. al., 1996). Fruit development has four identified stages: 1) white; 2) pink; 3) bright-red, and 4) dark red. Perez and colleagues (1996) identified ripening, maturation, as occurring during late stage three and early stage four.

To report color, at any stage of development, researchers can either use subjective color analysis (comparison of fruit with color chips of a recognized institution) or objective color analysis (measurement with a colorimeter). Colorimeter readings are a set of Cartesian coordinates generated by the instrument, which without algebraic manipulation do not quantify the hue (color) or the chroma (degree of gray to pure color) (McGuire, 1992). The colorimeter, reporting coordinates based on integrated spectral responses, functions best to measure color differences (Voss, 1992). This objective color analysis of strawberry fruit has been investigated in 
regards to genetic inheritability for breeding of color (Shaw, 1991; Sacks and Shaw, 1994; Shaw and Sacks, 1995). In all three studies, fully red fruit were harvested in the middle of the production season and measured twice externally and internally with a tristimulus colorimeter. They did not relate this date to the stages as identified by Perez et al. However, they made a reference to not using 'over-ripe' fruits. In the 1994 study, Sacks and Shaw determined that between 7 to 22 fruits would be needed to report color measurements with a $95 \%$ confidence interval.

Evaluating Capsicum annuum (L.) cv. 'Americano' and 'Fibola' grown in a nutriculture system, chroma was higher in the sand than in the perlite (Navarro et al., 1999). In 1997, Lancaster and colleagues compared color readings with chlorophyll, anthocyanin, and carotenoid pigments. They reported linear relationships between hue angle with anthocyanin and lightness $\left(\mathrm{L}^{*}\right)$ with the log of chlorophyll concentration. They also report, that each color point can be described in various combinations of pigments, however not a specific combination.

OBJECTIVES: To evaluate fruit color of Fragaria $\mathrm{x}$ ananassa grown in either rockwool or coal bottom ash and with either full or half strength hydroponic nutrient solution. To evaluate fruit color of differing cultivars grown in either rockwool or coal bottom ash.

\section{MATERIALS AND METHODS}

Strawberry fruit from the plants grown in both the 'Fresca' study (Chapter 4) and the cultivar study (Chapter 5) were harvested as the fruit reached full red, between stage 3 and stage 4 (Perez et al., 1996). They were harvested with cap and pedicle intact. Within 1 hour of harvest color measurements were taken with a Minolta tri-stimulus colorimeter (Minolta, Ramsey, NJ, USA). Recording the $\mathrm{L}^{*}$ (lightness, from black to white), $\mathrm{a}^{*}$ (blue-green to red-purple), and $b^{*}$ (yellow to blue) readings, the first external reading was 
measured from the darkest area, as determined visually, and the second from approximately $180^{\circ}$ around the berry. Internal readings were measured from opposite sides close to the tip of the fruit when cut in half from pedicle end to the tip. The chroma, hue and hue angle were calculated using the $\mathrm{L}^{*}$, $\mathrm{a}^{*}$ and $\mathrm{b}^{*}$ measurements and the Commission Internationale de l'Eclairage (CIE-LAB) formulas (Voss, 1992; McGuire, 1992).

All results were subjected to an analysis of variance for a general linear model with a randomized complete block factorial procedure on a statistical package for social sciences, SPSS (SPSS Inc., Chicago, IL). For factors with significant differences, the means were separated with Duncan's New Multiple Range method.

\section{RESULTS}

The 'Fresca' study (Chapter 4) to evaluate substrate and nutrient level effects found that color analysis of the fruit showed that fruit from plants grown in Pleasants coal bottom ash exhibited lower values in external lightness (Table 6-1). For external lightness $\left(L^{*}\right)$ the fruit grown in Albright coal bottom ash, Ft. Martin coal bottom ash and the rockwool control were of equal value. The largest values for external chroma, external hue and internal hue were from fruits grown in Ft. Martin coal bottom ash. The Albright coal bottom ash grown plants were equal to the rockwool control in all categories of color analysis. For the external chroma, external hue, internal chroma and internal hue the Pleasants coal bottom ash plants were statistically equal to those grown in the rockwool control but not those from the Albright or Ft. Martin coal bottom ashes. Color values were also higher for fruit grown with half strength nutrient solutions.

Color analysis of fruits from the different cultivars (Chapter 5) exhibited interactions between the cultivar and the substrate for the internal lightness, chroma and hue measurements (Table 6-2). However, the only 
interaction for external color occurred with hue. Most differences were due to cultivar. Separation of means for external lightness $\left(L^{*}\right)$ placed Cardinal berries significantly lighter than Crimson King or the darkest berries of either the Surecrop or Honeoye plants. The external chroma was darkest for the Surecrop berries, followed by the Cardinal, and then the berries from either Crimson King or Honeoye. The only factor which was significantly affected by substrate was the internal hue.

\section{DISCUSSION}

As color is also a characteristic of general berry appearance identified by Kader (1991), an increase in the chroma value (from gray to pure color) should be a desired goal. With the evaluation of external and internal chroma and hue, the fruit from plants grown in the Ft. Martin coal bottom ash exhibited statistically higher values than fruit from the other media (Table 6-1). It is possible that the fruit from the Ft. Martin coal bottom ash plants were supplied with some element that affected the ripening cascade of reactions that are as yet unidentified. Perez et al. $(1996,1997)$ reported that methyl jasmonate is indicated as involved in the ripening process as measured with color change and the correlation between flavor development and the activity of the enzyme AAT (alcohol acyltransferase). Increases in sugars during ripening are concurrent with color development and may be regulated by the same processes. On the other hand, there is limited correlation between color reporting and pigment analysis. In 1997, Lancaster et al. reported that chlorophyll, carotenoid, and anthocyanin could not be predicted from spectrophotometric measurements for fruits with complex pigment profiles. They found that more than one combination of pigments can be used to determine a given set of color coordinates. In the case of strawberry juice, high pressure liquid chromatographic analysis for anthocyanin composition and color characteristics has confirmed the complexity of color for this fruit with 13 identified anthocyanins (Bakker et al., 1994), thereby limiting our ability to speculate on pigment content 
based on spectrophotometric instrumental color measurements for strawberry fruit. However, the Ft. Martin coal bottom ash grown plants contained higher levels of calcium, aluminum, boron (significantly), iron, manganese, and zinc (Table 5-2). One or more of these may be linked with this increase in color intensity. Navarro and colleagues (1999) found that red pepper (Capsicum annum) red carotenoids for 'Americano' were higher in the perlite substrate, while the content was higher in the sand substrate for the cultivar 'Fibola'. They did not report any elemental analysis with this color data.

The interactions observed between cultivar and substrates for internal color may have been adversely affected by the fruit size. Fragaria fruit often exhibit an interior color that becomes lighter (more white) closer to the interior cavity. This is more pronounced in some varieties and if the fruit were small enough would influence the field of reflectance used in the tristimulus colorimeter measuring the color. 'Surecrop' berries are often advertised to have a solid red internal color. This would be supported by the internal lightness value of 44.44 and an internal hue of 0.755 , the highest values for these characteristics in this study. The 'Surecrop' berries also measured darkest for external chroma and lightness. 'Crimson King', despite the name, measured consistently lower in all internal color values. As previously discussed in the Fragaria x ananassa cv. 'Fresca' substrate study section of the discussion, strawberry fruit content of chlorophyll, carotenoid, and anthocyanin could not be predicted from spectrophotometric measurements for fruits with complex pigment profiles (Lancaster et al., 1997). High pressure liquid chromatographic analysis of strawberry juice for anthocyanin composition and color characteristics has confirmed the complexity of color with 13 identified anthocyanins (Bakker et al., 1994). These reports confirm limits to our ability for speculating on pigment content based on instrumental color measurements for strawberry fruit. 
The 'Surecrop' berries while not significantly different from the four other cultivars in calcium, magnesium, aluminum, boron, and zinc (Table 5-2), may have responded to the ratio of one element to another, in terms of color development. The calcium to magnesium ratio of 'Surecrop' is 4:1 compared to 'Crimson King' which is 3.2:1 (Table 5-2). The 'Surecrop' berries were also significantly higher in manganese (145.58 mg. kg-1 dry weight) than the 'Crimson King' berries (90.23 mg.kg-1 dry weight). The 'Crimson King' were however higher in boron (308 $\mathrm{mg} \cdot \mathrm{kg}^{-1}$ dry weight) than the 'Surecrop' (287.5 $\mathrm{mg} \cdot \mathrm{kg}^{-1}$ dry weight). The 'Surecrop' also had the highest level of aluminum with $71.4 \mathrm{mg} \cdot \mathrm{kg}^{-1}$ on a dry weight basis (Table 5-2). Although these differences in nutrient accumulation may reflect varietal characteristics and may have no bearing on color development. Navarro and colleagues (1999) found that red pepper (Capsicum annum) cultivars differed in their color development and pigment analysis. However, they did not report any elemental analysis with this color data.

The mechanism of fruit softening has not been identified. "Ripening in strawberries, marked by color change and softening, may result from a regulatory relationship between $\mathrm{ABA}$ and auxin levels, and the mechanization for this regulation must occur prior to the white color stage." (Perkins-Veazie, 1991). Subjecting strawberry fruits in the green stage to methyl jasmonate increased fruit respiratory activity and ethylene production in the immature berries. There was also observed "a transitory induction of anthocyanin biosynthesis and chlorophyll degradation" indicating a possible role of methyl jasmonate in the non-climateric strawberry fruit similar to climateric fruits (Perez et al., 1997). In 1996, this group of researchers reported that there was a "good coorelation between AAT [alcohol acyltransferase] and flavor quality in strawberries." For ripening in strawberry fruit two enzymes, polygalacturonase and pectin methyl-esterase, commonly associated with fruit softening, were not found 
Table 6-1: Mean color measurements taken $\sim 180^{\circ}$ from each other of fully red fruit of Fragaria x ananassa cv. 'Fresca' grown in rockwool control, Albright coal bottom ash (CBA), Pleasants CBA, or Ft. Martin CBA with either half or full strength nutrient solutions.

\begin{tabular}{|c|c|c|c|c|c|c|}
\hline & \multicolumn{3}{|c|}{ External $z$} & \multicolumn{3}{|c|}{ Internal $\mathrm{z}$} \\
\hline & $\mathrm{L}^{*}$ & Chromay & Hue $^{\text {y }}$ & $\mathbf{L}^{*}$ & Chromay & Hue $^{\text {y }}$ \\
\hline Rockwool & $38.86^{a}$ & $6.51^{b c}$ & $0.643 \mathrm{bc}$ & $50.02^{\mathrm{ab}}$ & $6.01 \mathrm{bc}$ & $0.483 \mathrm{bc}$ \\
\hline Albright CBA & $38.18 \mathrm{a}$ & $7.72 \mathrm{~b}$ & $0.790 \mathrm{~b}$ & $49.98 \mathrm{ab}$ & $7.45 \mathrm{ab}$ & $0.601 \mathrm{~b}$ \\
\hline Pleasants CBA & $33.38^{b}$ & $4.71^{c}$ & $0.556^{c}$ & $47.69 \mathrm{~b}$ & $5.15^{c}$ & $0.437^{c}$ \\
\hline Ft. Martin CBA & 40.97 a & $10.92^{a}$ & $0.978^{a}$ & $55.16^{a}$ & $9.13^{a}$ & $0.781^{a}$ \\
\hline Half & 38.74 & 9.10 & 0.897 & 52.41 & 8.46 & 0.691 \\
\hline Full & 38.03 & 5.83 & 0.587 & 49.80 & 5.41 & 0.418 \\
\hline \multicolumn{7}{|l|}{ Significancew } \\
\hline Substrate (sub) & $* *$ & $* *$ & $* *$ & $* *$ & $* *$ & $* *$ \\
\hline Solution (nutr) & * & $* *$ & $* *$ & $* *$ & $* *$ & $* *$ \\
\hline Sub * Nutr & NS & $* *$ & $* *$ & NS & $* *$ & $* *$ \\
\hline
\end{tabular}

z Means separated by Duncan's New Multiple Range

$\mathrm{y}$ chroma $=\operatorname{sqrt}\left(\mathrm{a}^{2}+\mathrm{b}^{2}\right)$

$\times$ hue $^{\mathrm{o}}=\arctan (\mathrm{b} / \mathrm{a})$

w NS, *, **, not significant, significant at the $\alpha=0.05$ level, significant at the $\alpha=0.01$ level respectively 
Table 6-2: Mean color measurements taken $~ 180^{\circ}$ from each other of fully red fruit of four Fragaria x ananassa cultivars grown in either Ft. Martin coal bottom ash (CBA) or rockwool control (RW).

\begin{tabular}{|c|c|c|c|c|c|c|}
\hline & \multicolumn{3}{|c|}{ External $^{z}$} & \multicolumn{3}{|c|}{ Internal $^{z}$} \\
\hline & $\overline{L^{*}}$ & Chromay & Hue ${ }^{\text {ox }}$ & $\overline{L^{*}}$ & Chromay & Hue $^{\text {ox }}$ \\
\hline Crimson King & $38.33^{b}$ & $35.30^{c}$ & 0.752 & 40.43 & 43.68 & 0.732 \\
\hline Cardinal & $40.28^{a}$ & $38.89^{\mathrm{b}}$ & 0.768 & 41.80 & 45.49 & 0.741 \\
\hline Surecrop & $36.51^{\mathrm{c}}$ & $41.96^{a}$ & 0.585 & 44.44 & 44.46 & 0.755 \\
\hline Honeoye & $37.01 b^{c}$ & $35.73^{c}$ & 0.700 & 42.08 & 46.72 & 0.746 \\
\hline Ft. Martin CBA & 37.82 & 37.73 & 0.695 & 41.68 & 45.10 & 0.725 \\
\hline Rockwool (RW) & 38.24 & 38.21 & 0.707 & 42.69 & 45.08 & 0.763 \\
\hline \multicolumn{7}{|l|}{ Significancew } \\
\hline Cultivar (cv) & $* *$ & $* *$ & $* *$ & ** & $* *$ & NS \\
\hline Substrate (sub) & NS & NS & NS & NS & NS & $* *$ \\
\hline $\mathrm{Cv} * \mathrm{Sub}$ & NS & NS & $* *$ & $* *$ & $* *$ & $* *$ \\
\hline
\end{tabular}

z Means separated by Duncan's New Multiple Range

y $\operatorname{chroma}=\operatorname{sqrt}\left(\mathrm{a}^{2}+\mathrm{b}^{2}\right)$

$\times$ hue $^{o}=\arctan (\mathrm{b} / \mathrm{a})$

w NS, * **, not significant, significant at the $\alpha=0.05$ level, significant at the $\alpha=0.01$ level respectively 


\section{CHAPTER 7}

\section{FLAVOR ANALYSIS OF FRAGARIA X ANANASSA FRUIT}

\section{LITERATURE REVIEW}

Although consumers often base their initial purchasing decision on appearance, the decision to purchase the same product again depends on "flavor and other characteristics affecting fruit quality" (Galletta and Himelrick, 1990). Flavor is a complex combination of both taste and smell. For the strawberry, flavor quality has been linked to the sugar to acid ratio. As the fruit matures, the sugars increase and the acids decrease. Sugars may arise from imports, on site synthesis, or starch hydrolysis. They are mostly glucose and fructose, $83 \%$ of total ripe fruit sugars. The sugars are considered to be precursors to flavor compounds, furanones, and for color compounds, anthocyanins. The acids may decrease through the tricarboxylic acid cycle (TCA), respiratory metabolism, and/or by dilution as the fruit cells enlarge and hold more water.

Flavor is also associated closely with the aroma compounds the fruit releases either intact or when macerated (chewed). Many studies have identified, through various methods, 282 flavor compounds for Fragaria x ananassa and 91 flavor compounds for Fragaria vesca, all of which are also in the Fragaria $\mathrm{x}$ ananassa (Zabetakis and Holden, 1997). These studies employed isolation and concentration methods like steam distillation, liquid-liquid extraction, liquid-solid extraction, and headspace trapping followed by concentration techniques to remove the solvent and leave only the compounds of interest which are often present in minute quantities. The compounds liberated during these methods are then identified through gas chromatography (GC), GC plus mass spectrometry (GCMS), nuclear magnetic resonance (NMR) or high pressure liquid chromatography (HPLC). The 282 compounds currently identified represent 11 chemical classes, 
acetals, acids, alcohols, aldehydes, esters, furans, ketones, lactones, terpenes, sulfur componds, and $\beta$-D-glyco-pyranosides.

The most commonly used extraction for strawberry fruit is liquid - liquid extraction with the aid of organic solvents (Zabetakis and Holden, 1997).

This process can utilize one or a combination of organic solvents that will retain compounds that are highly volatile, and separate the compounds from the matrix of the fruit tissue/juice. Many strawberry aroma compounds are esters (102 of 282 identified compounds) and solvent choice is largely influenced by these compounds when interest is in the flavor profile. A mixture of diethyl ether and pentane is used for the sensitivity of the diethyl ether for compounds that are not soluble in pentane alone. And by using the mixture the pentane, being very non-polar, allows for easy separation of the phases. The mixture holds little water and does not require drying over sodium sulfate (Larsen and Poll, 1995).

\section{OBJECTIVE}

To evaluate substrate, nutriculture nutrient level, and cultivar affects on the production of flavor compounds and flavor profiles for the strawberry fruit.

\section{MATERIALS AND METHODS}

After color readings were recorded (Chapter 6) the fruit halves were frozen, within 2 hours of harvest and stored, in zip lock sample bags until juiced in the lab for flavor compound extraction. The fruits were crushed while frozen, with mortar and pestle, and the juice filtered under vacuum, Whatman's \#42 filter paper. This juice was then held at $0 \mathrm{C}(32 \mathrm{~F})$ in a refrigerator until extraction. Twenty grams of this juice was extracted with ether:pentane (2:1, v:v) solvent (Larsen and Poll, 1995). This solvent solution was held in a salt water ice bath to reduce volatilization until it was added to the juice in a separatory funnel. After mixing the two solutions by hand 
with occasional venting, the supernatant fluid was collected and held at OC $(32 \mathrm{~F})$ until it could be reduced in volume by removing the ether:pentane mixture under vacuum at $18 \mathrm{C}(65 \mathrm{~F})$ (Labconco Standard Rotary Evaporator 421-1659). The resulting concentrate was then held at OC (32F) until injection into the GC for flavor compound analysis.

Gas chromatographic analysis of the concentrate was performed with a Hewlett-Packard 5890 GC (Hewlett Packard Company, Avondale , PA, USA) with a Suplecowax $30 \mathrm{~m}$ x $25 \mu \mathrm{m}$ x $25 \mathrm{~mm}$ capillary column (Supleco, Bellefonte, PA). A liquid sample, $20 \mu$, was injected into a 1:10 split inlet at $220 \mathrm{C}$. The oven temperature was programmed at $50 \mathrm{C}$ for 10 minutes, then increased $4 \mathrm{C} \cdot$ minute $^{-1}$ to $140 \mathrm{C}$, and held at this temperature for 30 minutes. The compounds were detected with flame ionization at $240 \mathrm{C}$.

\section{RESULTS}

\section{QUANTITATIVE ANALYSIS OF FLAVOR COMPOUNDS 'FRESCA' STUDY}

After the initial solvent peak grouping, two samples (Pleasants coal bottom ash and Rockwool) eluted eight peaks in large enough quantity to be registered by the GC integrator (attenuation at -2 ): 22.5, 26.6, 27.3, 28.5, 29.8, 35.4, 36.5, and 37.6 minutes (Table 7-1). Peak areas show a similar pattern for these two samples. The third peak (27.3 minutes) is larger than the second (26.6 minutes), which in turn is larger than the first peak (28.5 minutes). The third peak (27.3 minutes) is larger than the fourth peak (28.5 minutes). However, it is smaller than the fifth peak (29.8 minutes). For both samples, the fifth peak (29.8 minutes) is smaller than the sixth peak (35.4 minutes) and the seventh peak (36.5 minutes) is smaller than the eighth peak (37.6 minutes). There are two contrasts between the Pleasants coal bottom ash grown fruit profile and the Rockwool grown fruit profile. The first contrast is the relationship of the sixth peak (35.4 minutes) and the eighth 
peak (37.6 minutes). For the Pleasants coal bottom ash the sixth peak was 1.6 times larger than the eighth peak. The Rockwool grown fruit profile reversed this and the eighth peak was 1.9 times larger than the sixth peak. The second contrast is for the relationship of the seventh peak (36.5 minutes) with both the sixth (35.4 minutes) and eighth (37.6 minutes) peaks. The Pleasants coal bottom ash grown fruit profile showed the sixth peak to be 5.8 times larger and the eighth to be 3.5 times larger than the seventh. For the Rockwool grown fruit profile the difference is that the sixth is 14.4 times larger and the eighth is 26.7 times larger than the seventh peak.

The fruit from plants grown in either the Albright coal bottom ash or the Ft. Martin coal bottom ash eluted only 5 of these eight peaks, those at 27.3, 29.8, 35.4, 36.5, and 37.6 minutes (Table 7-1). These two substrates, similar to those already discussed, showed a larger peak at 29.8 minutes than the peak at 27.3 minutes. Also similar are the 35.4 minute peak and the 37.6 minute peak both being larger than the one between them at 36.5 minutes. However, when comparing the peaks of 35.4 and 37.6 minutes to each other both substrates have the largest peak at the 35.4 minute elution time. The Albright coal bottom ash grown fruit profile has a more pronounced difference in the relationship of the last three peaks with the peak at 35.4 minutes being 6.6 times larger than the peak 36.5 minutes and 5.1 times larger than the peak at 37.6 minutes. This profile also shows the peak at 37.6 minutes to be 1.3 time larger than the peak at 36.5 minutes. In contrast to this the Ft. Martin coal bottom ash grown fruit profile shows a much more even relationship between these three peaks with the peak at 35.4 minutes being only 2.7 times larger than the peak at 36.5 minutes and 1.1 times larger than the peak at 37.6 minutes. The peak at 37.6 minutes is 2.6 times larger than the peak at 36.5 minutes. 


\section{CULTIVAR STUDY}

In this study, cultivar differences were clearly observed. However, there were still identifiable differences due to substrates. The cultivar 'Crimson King' flavor profile for fruit grown in rockwool eluted 14 identified peaks. When grown in coal bottom ash the fruit profile of 'Crimson King' identified 8 of

these 14 peaks. The cultivar 'Honeoye' fruit flavor profile identified only 6 peaks for the rockwool grown plants and 3 peaks for the coal bottom ash grown plants (Table 7-2). The one consistency regardless of cultivar or substrate was the largest peak eluted at 34.9 minutes.

For the 'Crimson King' fruit the peak at 34.9 minutes was followed in descending peak areas by the peaks of 29.8, 28.5, and 55.2 minutes. The peak at 34.9 minutes is 4.1 times larger than the 29.8 minute peak, 4.4 times larger than the 28.5 minute peak, and 5.5 times larger than the 55.2 minute peak for the fruit grown in the coal bottom ash. For the rockwool grown fruit the peak at 34.9 minutes was 2.9 times larger than the 29.8 minute peak, 4.7 times larger than the 28.5 minute peak, and 6.3 times larger than the 55.2 minute peak. Other than these ratio differences and the number of peaks measured are the differences between the 27.2 and the 26.5 minute peaks, and the 36.4 and the 40.2 minute peaks. For the coal bottom ash grown fruit these ratios were 2.5 times larger and 1.6 times larger, respectively. The fruit grown in rockwool displayed the ratios of 1.4 and 2.1 respectively.

The 'Honeoye' fruit profiles offer limited points for comparison. For the three peaks measured for the fruit grown in coal bottom ash the peak elluted at 34.9 minutes had the largest peak area. This was also the largest peak for the rockwool grown fruit. The coal bottom ash fruit showed the 34.9 minute peak to be 1.9 times larger than the 36.4 minute peak, whereas, the rockwool fruit showed it to be 4.8 times larger. The differences between 
34.9 minute and the 43.2 minute peaks are 1.7 times larger for the coal bottom ash fruit and 4.1 times larger for the rockwool grown fruit.

\section{QUALITATIVELY ANALYSIS OF FLAVOR COMPOUNDS 'FRESCA'}

Visual inspection of the chromatograms for the 'Fresca' fruit grown in rockwool or one of three coal bottom ashes indicates the complexity of the flavor profiles (Figure 7-1). Each chromatogram displayed many more peaks than the machine registered large enough for measurement. The profile for the Albright coal bottom ash was visually similar to the Ft.Martin coal bottom ash profile, particularly the peaks from the 20 minute mark up to the first recorded peak at 27.3 minutes (Figure 7-1).

As with the quantitative analysis, the Pleasants coal bottom ash profile and the rockwool profile while similar to each other were distinctly different from the Albright coal bottom ash and the Ft. Martin coal bottom ash profiles. There are more peaks visible on the Peasants coal bottom ash and the rockwool profiles between the 29.8 minute peak and the 35.4 minute peak than on the profiles of the other two coal bottom ashes. There are also more discernible peaks following the 37.6 minute peak for both profiles.

\section{CULTIVAR STUDY}

Visual inspection of the profiles for both the 'Crimson King' (Figure 7-2) and the 'Honeoye' (Figure 7-3) indicates slightly more complexity for the rockwool profiles than for the coal bottom ash profiles. Particularly in the time frame from 30 to 40 minutes retention time and again later in the profile around the 45 to 50 minute retention time.

There are clearly differences between the cultivars. The 'Crimson King' fruit in both substrates produced profiles with a greater complexity of flavor 
compound peaks, particularly in the 20 to 30 minute and in the 35 to 45 minute time frames.

\section{DISCUSSION}

Flavor analysis is complex considering all the physiological and psychological processes involved in the human perception of flavor. The sensation of flavor is a combination of aroma (prior to and during chewing), taste, and the preconceived concept of what the product should taste like. Traditional flavor analysis has relied heavily on the taste aspect of foods with the analysis of sugars, acid, salts, and combinations or ratios of these basic categories to describe the product being evaluated.

With the development of gas and high pressure liquid chromatography and the refinement of the techniques for each, flavor analysis became more dependent on the identification and relationships of individual chemical components in a flavor profile. While the qualitative and quantitative composition of the strawberry fruit is described (Zabetakis and Holden, 1997), cultural effects on the biosysnthesis and compound relations within a profile have not been reported.

The results of this analysis indicate that the characteristic strawberry aroma and flavor are linked to both cultivar (genetic inheritance) and root substrate (environmental conditions). As observed by Zabetakis and Holden (1997) the strawberry has "one of the most complicated fruit flavors". However, their quest for producing a natural strawberry flavor based on the qualitative and quantitative analyses that have produced the listing of most compounds in the flavor profile does not consider the differences in the cultivar flavors. The results presented here confirm the complexity of the flavor profile for the strawberry. They also illustrate the interaction of the plants with their environment, in this case specifically the root media and the nutrient solution. 
The similarity of the ratio profiles for the Albright coal bottom ash and the rockwool control grown fruit when compared against the coal bottom ashes from the Pleasants and Ft. Martin power plants, indicates that media differences may play a significant role in the uptake of nutrients which may affect the biosynthesis of fruit color and flavor profile. This medium effect may have been due to textural differences between the ashes. Even though all the ash was screened to remove particles larger than $1 \mathrm{~mm}(0.25 \mathrm{inch})$ it was observed, but not quantified, that the Albright coal bottom ash had a more sand like quality and may have compacted in the root zone. This may have reduced the size of the air spaces and created a moisture retention situation similar to the rockwool. The coal bottom ashes from both the Pleasants and Ft. Martin power plants had larger particles mixed with small creating a more gravel/cinder like substrate.

The chemistry of the ashes themselves seem to play a limited role in the plant response as measured by nutrient uptake, fruit color and fruit flavor profile. When the chemistry of the coal bottom ashes was analyzed by energy dispersive spectroscopy the Albright coal bottom ash was statistically the same as the Ft. Martin coal bottom ash. The Pleasants coal bottom ash was totally different from the other two coal bottom ashes, with several unidentified peaks and high alpha iron oxide level $\left(\mathrm{Fe}_{2} \mathrm{O}_{3}\right)$ (Renton, 1994). These results do not match with the Albright coal bottom ash producing results similar to the rockwool and the Pleasants coal bottom ash being similar to the Ft. Martin coal bottom ash. Therefore, the structural chemistry of the ashes themselves should have a minimal influence on the plant and fruit characteristics measured in these studies.

The flavor profile analyses of the different cultivars, grown in either coal bottom ash or rockwool, confirms that there are cultivar distinctions in flavor. Both the 'Cardinal' and the 'Honeoye' fruits produced distinctly different flavor profiles. Since cultivars are normally bred for different 
characteristics based on market and area of production, these flavor profile differences may be accounted for by their parentage. The 'Cardinal' came from a crossing of 'Earlibelle' and AR5063, while the 'Honeoye' is from a 'Vibrant' and 'Holiday' cross. Both cultivars were released into production during the 1970's. However, 'Cardinal' was bred for the southeastern production region of the United States, while 'Honeoye' was developed for the northeastern region. In a 1989 study, Scheerens and Brenneman found that both the 'Cardinal' and the 'Honeoye' scored the same in a panel test for flavor. They both were described in the category which ranked them as pleasant and strawberry like for aroma. They ranked equally for soluble solids and for acidity. The main differences reported for these two cultivars were that the 'Honeoye' had firmer berries and the 'Cardinal' had lighter external color.

Due to equipment restrictions the identification of the individual peak compounds was not possible using a gas chromatograph without an associated mass spectrometer. It is also conceivable that some of the most volatile compounds were not measured since the fruit was frozen in ziplock plastic bags instead of glass containers (Larsen and Poll, 1995). Also the extraction of press juice and subsequent concentration, solvent removal, method used was a modification of the Larsen and Poll (1995) procedure and may have failed to retain the volatile compounds. This could have been confirmed had an internal standard been spiked into the samples at a known concentration or if an external standard complex been run for establishment of calibration curves. The profile would have been more complete if a combination of headspace sampling and concentrated column loading could have been used. It would be interesting to repeat these measurements using the newly developed solid phase micro-extraction fibers as reported by Song et al. (1998) for strawberry headspace aroma analysis. 
Table 7-1: Peak areas of gas chromatograms for Fragaria $\mathrm{x}$ ananassa cv.

'Fresca' fruit grown in one of three coal bottom ashes or rockwool substrate.

\begin{tabular}{lrrrr}
\hline $\begin{array}{l}\text { Peak retention } \\
\text { time in minutes }\end{array}$ & Albright & Ft. Martin & Pleasants & Rockwool \\
\hline $\mathbf{2 2 . 5}$ & & & 5434 & 4690 \\
$\mathbf{2 6 . 6}$ & & & 8615 & 5288 \\
$\mathbf{2 7 . 3}$ & 5841 & 5038 & 12390 & 9719 \\
$\mathbf{2 8 . 5}$ & & & 11318 & 6719 \\
$\mathbf{2 9 . 8}$ & 9923 & 7890 & 34768 & 13181 \\
$\mathbf{3 5 . 4}$ & 37264 & 29040 & 72328 & 47054 \\
$\mathbf{3 6 . 5}$ & 5630 & 10609 & 12576 & 3271 \\
$\mathbf{3 7 . 6}$ & 7319 & 27160 & 44911 & 87372 \\
\hline
\end{tabular}


Table 7-2: Peak areas of gas chromatograms for Fragaria $\mathrm{x}$ ananassa cv. 'Crimson King' and 'Honeoye' fruit grown in coal bottom ash (CBA) or rockwool (RW) substrate.

\begin{tabular}{|c|c|c|c|c|}
\hline \multirow{2}{*}{$\begin{array}{l}\text { Peak retention } \\
\text { time in minutes }\end{array}$} & \multicolumn{2}{|l|}{ Crimson King } & \multicolumn{2}{|l|}{ Honeoye } \\
\hline & CBA & RW & CBA & $\mathbf{R W}$ \\
\hline 22.5 & & 5622 & & \\
\hline 26.5 & 4277 & 13492 & & \\
\hline 27.2 & 10820 & 18361 & & \\
\hline 28.5 & 21134 & 37239 & & 20091 \\
\hline 29.8 & 22623 & 60951 & & 12505 \\
\hline 32.9 & & 4798 & & \\
\hline 34.9 & 92283 & 175491 & 8847 & 63184 \\
\hline 35.8 & & 10105 & & \\
\hline 36.4 & 10294 & 17332 & 4737 & 13117 \\
\hline 39.9 & & & & 4322 \\
\hline 40.2 & 6573 & 8154 & & \\
\hline 40.6 & & 7422 & & \\
\hline 43.2 & & 4973 & 5157 & 15475 \\
\hline 55.2 & 16669 & 27717 & & \\
\hline 58.3 & & 27225 & & \\
\hline
\end{tabular}


Figure 7-1: Flavor compound gas chromatograms for Fragaria $\mathrm{x}$ ananassa cv. 'Fresca' grown in nutriculture in greenhouse for substrate analysis, time line on each profile for 0 to 60 minutes.

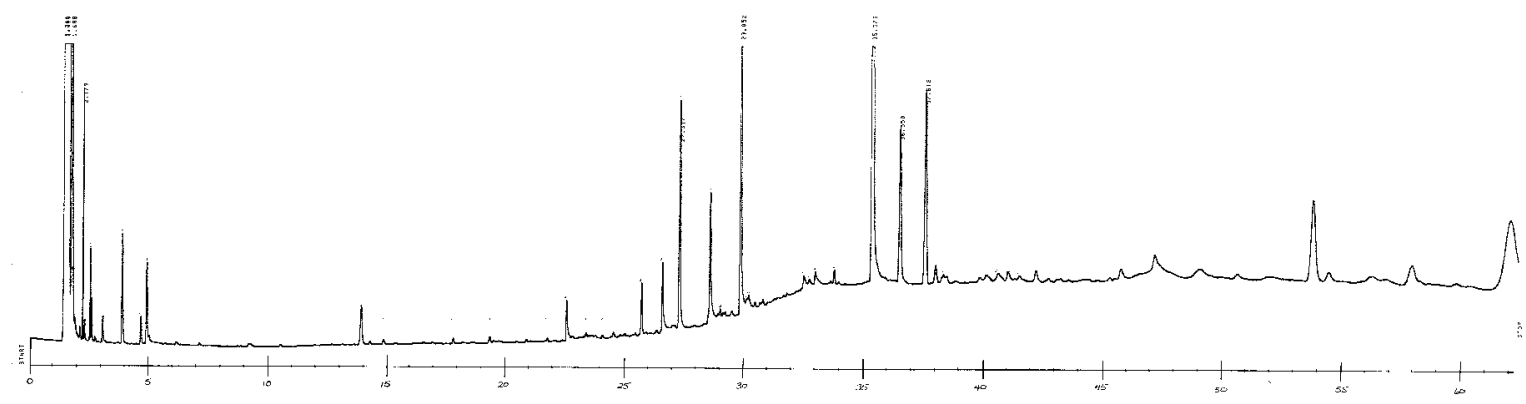

Albright CBA with half strength nutrient solution

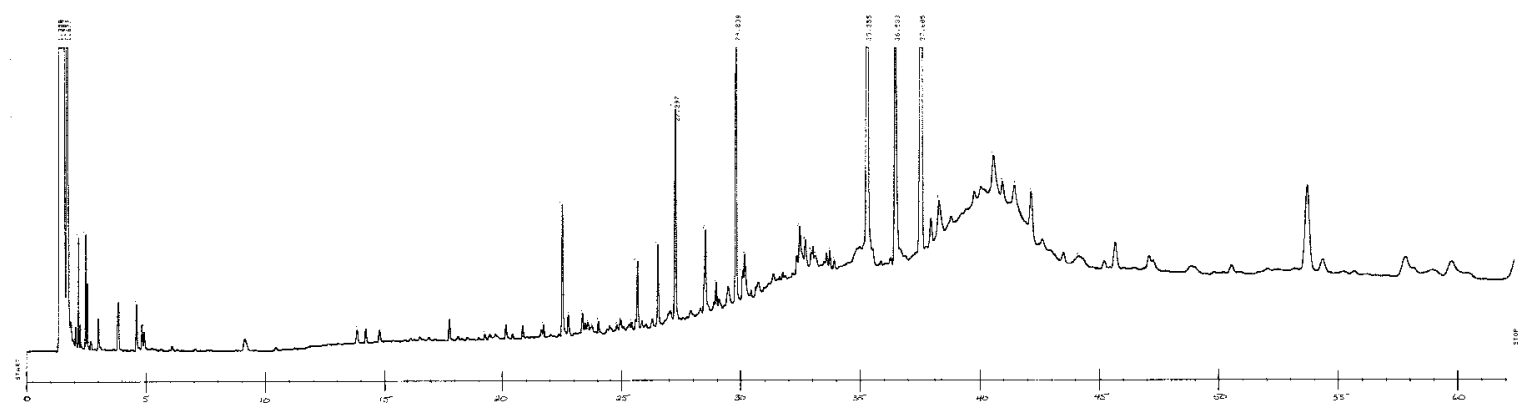

Fort Martin CBA with half strength nutrient solution

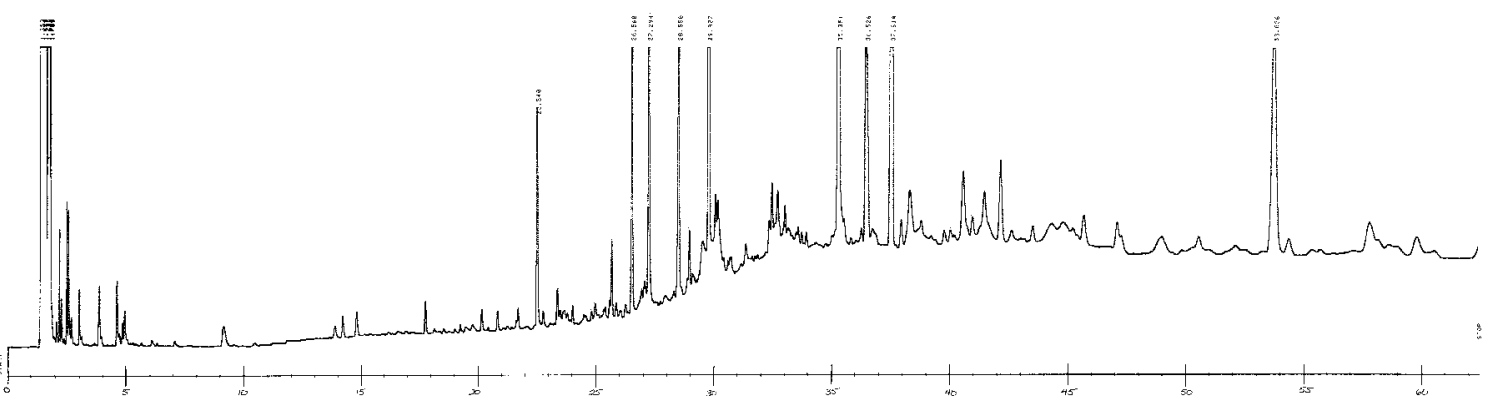

Pleasants CBA with half strength nutrient solution

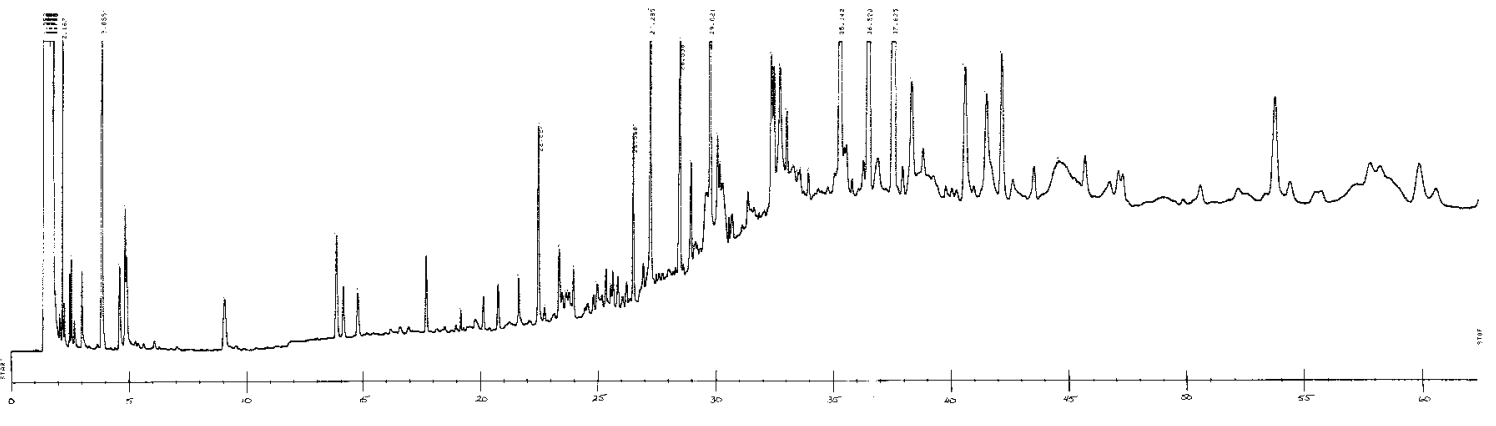

Rockwool with half strength nutrient solution 
Figure 7-2: Flavor compound gas chromatograms for Fragaria $\mathrm{x}$ ananassa cv. 'Crimson King' grown in nutriculture in greenhouse for substrate analysis, time line on each profile for 0 to 60 minutes.

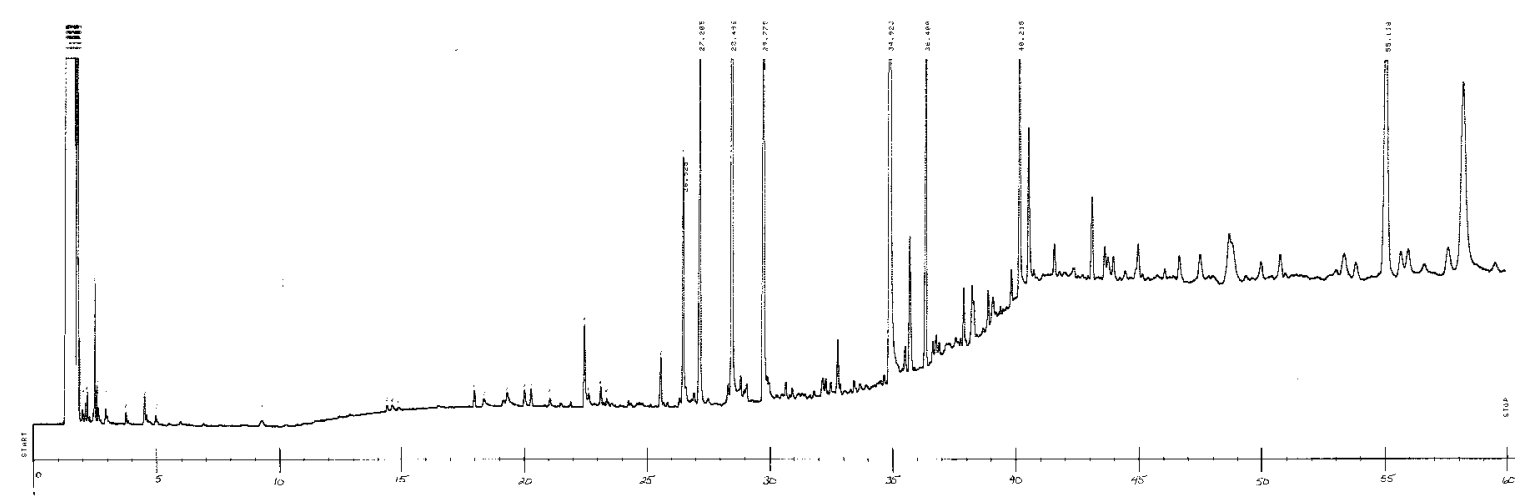

CBA

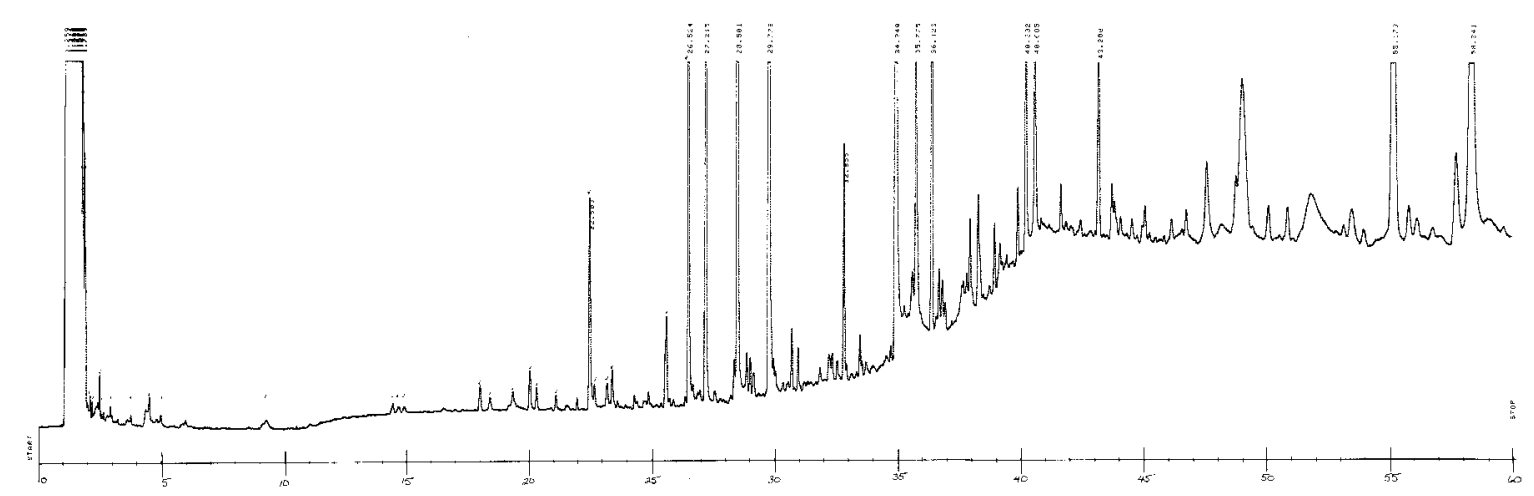

\section{RW}


Figure 7-3: Flavor compound gas chromatograms for Fragaria $\mathrm{x}$ ananassa cv. 'Honeoye' grown in nutriculture in greenhouse for substrate analysis, time line on each profile for 0 to 60 minutes.

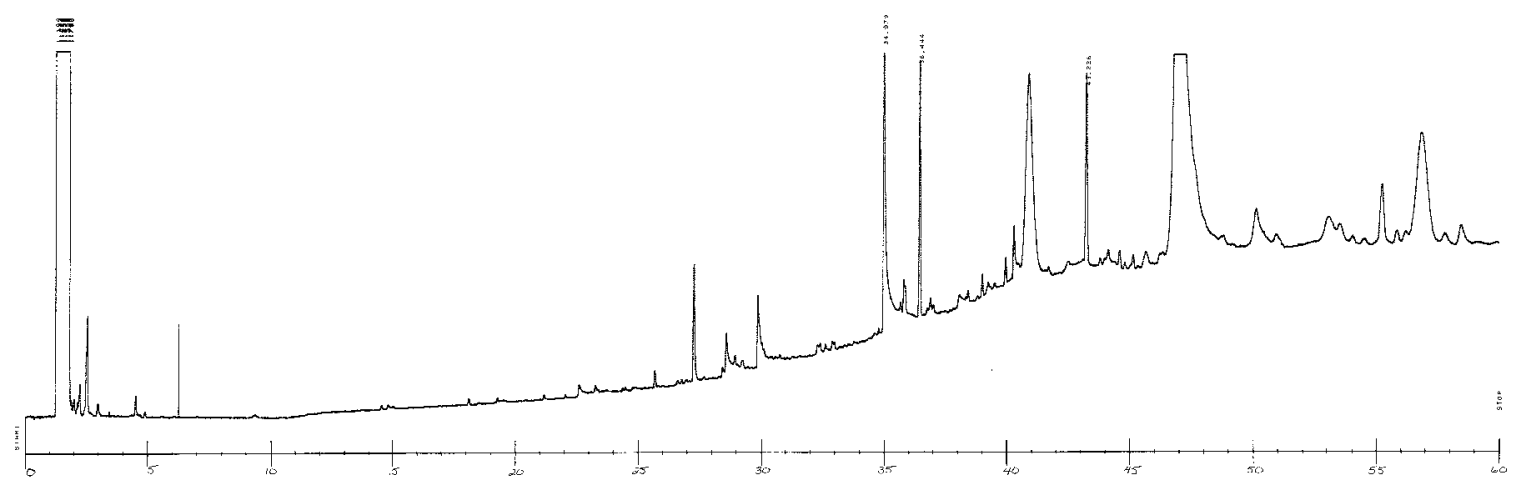

\section{CBA}

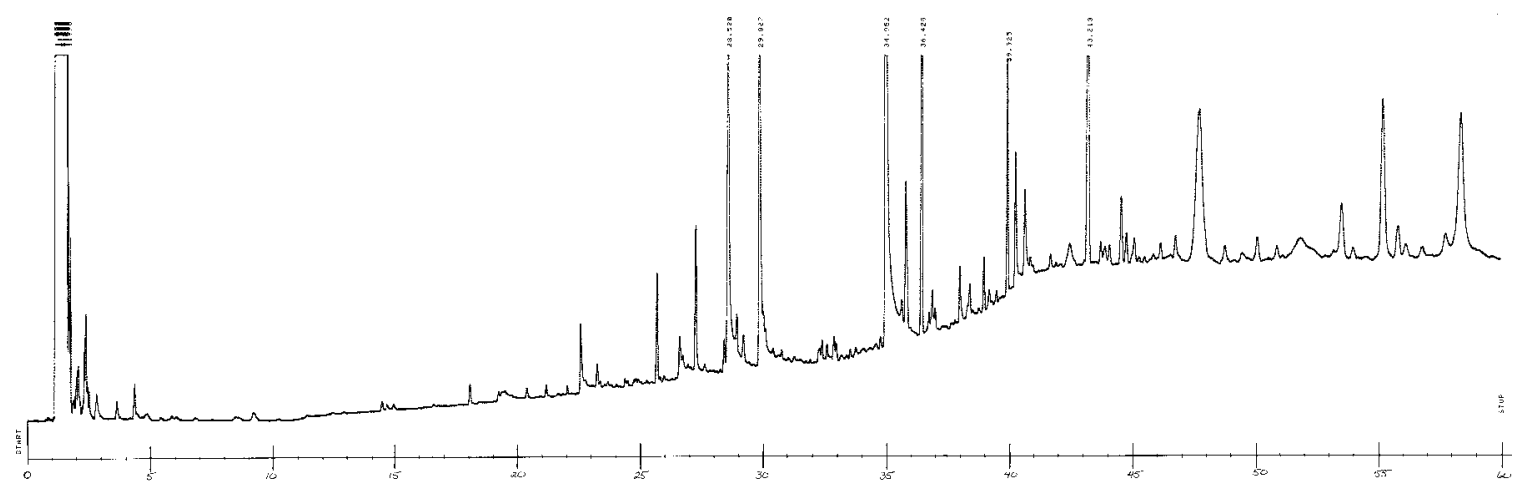

RW 


\section{CHAPTER 8}

\section{CONCLUSIONS AND FUTURE RESEARCH}

These combined studies have expanded the base of knowledge for greenhouse production of strawberries for both the high end retail garden center (plug and plant production) and the producer of off season fruit. The Europeans have long produced fruit for retail markets in greenhouse settings. By using their collective experience and the seed germination and plug production media results reported here, the fruit growers with season extending structures may now time fruit production for any time of the year. Using cool temperatures and controlled lighting the plants can be grown from seed to fruit for year round production of flavorful, locally grown fruit. As reported in Chapter 2, Fragaria x ananassa cv. 'Sweetheart' achenes exhibited enhanced germination with either cutting or scarification of the achene coat. In Chapter 3, Fragaria x ananassa cv. 'Fresca' exhibited higher germination percentages with either Sunshine plug mix or Grodan orchid greenmix.

The cultural influences on fruit color and flavor profile indicate the need for consideration by the commercial producer for cultivar and cultural protocol with the production of the strawberry, as well as the need for further scientific investigation. The cultivar 'Fresca' while showing no differences in plant growth characteristics due to nutriculture substrate, did have differences in fruit color characteristics, chroma and hue (Chapter 6). This cultivar also exhibited increased nutrient levels, above recommended amounts for boron, calcium, iron, and magnesium (Chapter 4). Comparing commercially available cultivars in either $100 \%$ Ft. Martin coal bottom ash or 100\% rockwool substrate (Chapter 5), no differences were found in plant growth parameters for substrate-cultivar interaction or substrate. The number of crowns, number of leaves, plant tissue content for iron, magnesium, and managese were influenced by cultivar. Color data for the 
different cultivars shows an interaction between cultivar and substrate for external hue and all internal color measurements (lightness, chroma, and hue). The external lightness and chroma were most affected by the cultivar (Chapter 6). Also reported in Chapter 7 , the flavor compounds/profiles are both quantitatively and qualitatively influenced by both cultivar and the culture of that cultivar. Further investigation of cultivar response to substrate is needed. By using different cultivars it may be possible to categorize cultivars based on their genetic inheritance (parentage) or their cultural region of adaptation. Investigations into the relationship between the flavor compounds and postharvest diseases, have been initiated by researchers at USDA-ARS (Vaughn et al., 1993) and at the University of Kentucky, Lexington (Archbold et al., 1997). Therefore, data on the quantitative and qualitative analyses of flavor compound production by various strawberry cultivars can be useful in refining their investigations.

Larsen and Poll have reported differences in aromatic compounds from strawberry due to freezing and thawing (1995) and by using juice or fruit tissue for analysis (1990). The reporting of strawberry flavor is also affected by the extraction procedure and the identification procedure (Zabetakis and Holden, 1997). This area of study could benefit from newly developed headspace collection and analysis techniques. One such method employs the use of solid phase micro extraction fibers (Song et al., 1998). Combining this new technology and the use of different cultivars, cultural practices, fresh versus frozen berries, and differing stages of berry maturation could lead to a base of knowledge, which could then be used to illuminate the flavor compound biosynthesis processes in the fruit.

The fruit biosynthesis of flavor compounds is another area for further research. The various enzymes and biosynthetic pathways have not been clarified for the strawberry fruit (Zabetakis and Holden, 1997). However, progress is being made. In Spain, Perez and colleagues have found that 
strawberry AAT (alcohol acyltransferase) was active against acetyl-CoA (100\%), butyl-CoA $(70 \%)$, and propyl-CoA $(20 \%)$. They report an increase in strawberry AAT activity as the fruit matures through the four stages of white, pink, bright red, and dark red for most cultivars they have studied. They also conclude that AAT plays a main role in strawberry fruit aroma biogenesis (1996). This same group reported that methyl jasmonate in vitro increased the respiratory activity, ethylene production, transitory induction of anthocyanin biosynthesis, and chlorophyll degradation for immature strawberry fruit (1997).

These studies are further complicated by the complexity of the flavor profile of the strawberry and the fact that the profile is affected by the cultivar being studied. With researchers located around the world, in different cultural areas for strawberry production, full elucidation of the biosynthesis of strawberry flavor will require not only collaboration between the parties, but also replications with different cultivars in different climates. Application of this knowledge can then be used in combination with postharvest and controlled atmosphere studies for delivery of a high quality, flavorful strawberry to the consumer.

As with all horticultural research, the refinement of the pure science elements and knowledge base should be done in the realization of the application of this research to help solve 'real world' problems. 


\section{BIBLIOGRAPHY}

Albregts, E.E. and C.M. Howard. 1985. Short term cold storage and soil fertility during plant and fruit production on growth and fruiting of Strawberry. HortScience. 20(3): 411-413.

Albregts, E.E., G.J. Hochmuth, C.K. Chandler, J. Cornell, and J. Harrison. 1996. Potassium fertigation requirements of drip-irrigated strawberry. J. Amer. Soc. Hort. Sci. 121(1): 164-168.

Archbold, D.D. and B. Zhang. 1991. Chapter 28: Drought stress resistance in Fragaria species. pp 138-143. In: In: A. Dale and J.J. Luby (eds). The strawberry into the $21^{\text {st }}$ century. Timber Press, Portland, OR, USA.

Awang, Y.B. and J.G. Atherton. 1994. Salinity and shading effects on leaf water relations and ionic composition of strawberry plants grown on rockwool. J. Hort. Sci. 69: 377-383.

Awang, Y.B., and J.G. Atherton. 1995. Effect of plant size and salinity on the growth and fruiting of glass house strawberry. J. Hort. Sci. 70: 257.262.

Awang, Y.B.; J.G. Atherton and A.J. Taylor. 1993. Salinity effects on strawberry plants grown in rockwool. II. Fruit quality. J. Hort. Sci. 68(5): 791-795.

Bakker, J., P. Bridle, and S.J. Bellworthy. 1994. Strawberry juice colour: a study of the quantitative and qualitative pigments composition of juices from 39 genotypes. J. Sci. Food Agric. 64: 31-37.

Bearce, B.C., D.L. Lentz, M.A. Woodard, and E.C. Townsend. 1993a. Coal bottom ash as a root substrate for marigolds in a closed loop nutriculture system. Pp 13-1 to 13-16. In: Proceedings: Tenth international ash use symposium. Vol 1: High-volume uses/concrete application EPR1 TR101774. Am. Coal Ash Assoc. Washington, D.C.

Bearce, B.C., M.A. Woodard, and E.C. Townsend. 1993b. Growth and flowering response of greenhouse chrysanthemums to coal bottom ash root media in a closed loop nutriculture system. Pp 46-63. In: Shiao-Hung Chiang (ed). Tenth annual Pittsburgh coal conference. Univ. of Pittsburgh, Pittsburgh, PA.

Beytes, C. 1997. One-on-one with five of America's best plug growers. GrowerTalks. April:30-38.

Biernbaum and Fonteno. 1996. Nutrient and water management seminar. Ohio Floriculture Short Course. Cincinatti, OH. 
Bringhurst, R.S. and V. Voth. 1957. Effect of stratification on strawberry seed germination. Proc. Amer. Soc. Hort. Sci. 70:144-149.

Butler, S.H. and B.C. Bearce. 1995. Greenhouse rose production in media containing coal bottom ash. J. Environ. Hort. 13(4): 160-164.

Carpenter, T.D. 1985. Chapter 21: United States of America: Current research and developments. In: A.J. Savage (ed). Hydroponics Worldwide: State of the art in soilless crop production.

Chandler, C.K. 1991. Chapter 8: North American strawberry cultivars. pp 60-65 .In: In: A. Dale and J.J. Luby (eds). The strawberry into the $21^{\text {st }}$ century. Timber Press, Portland, OR, USA.

Cluskey, S. 1989. Coal bottom ash and pinewood chips as substrate components with a recycled nutrient solution. MS Thesis, West Virginia University, Morgantown, WV.

Darrow, G.M. 1966. The Strawberry. Holt, Rinehart, and Winston, NY, NY, USA

El Ghaouth, A., J. Arul, J. Grenier, and A. Asselin. 1991. Glucanohydrolases and inhibitory activity to Botrytis cinerea in extracts from strawberry fruits. Can. J. Pl. Path. 13: 315-320.

Esensee, V.; H. Hughes, and G.Volk. 1991. Chapter 21: In vitro evaluation of straberry (Fragaria spp.) seedlings for salt tolerance. pp 118-120. In: In: A. Dale and J.J. Luby (eds). The strawberry into the $21^{\text {st }}$ century. Timber Press, Portland, OR, USA.

Galletta, G.J. 1989. Northeastern United States strawberry cultivars. Fruit Var. J. 43: 31-33.

Galletta, G.J. and R.S. Bringhurst. 1990. Chap.3: Strawberry Management, pp 83-156. In: Galletta G.J. and D. Himelrick (eds). Small Fruit Crop Management. Prentice-Hall Inc. publishers.

Galletta, G.J. and D.G. Himelrick. 1990 Small Fruit Crop Management. Prentice-Hall Inc. publishers.

Geater, C.A., G.R. Nonnecke, W.R. Graves, A.S. Aiello, and C.A. Dilley. 1997. High root zone temperatures inhibit growth and development of Fragaria species. Fruit Varieties J. 51(2): 94-101.

Gritt, A. 1999. Personal communication. Eleanor, WV. 
Harless, S. 1994. Happy with rockwool, grower moving more roses out of soil. Greenhouse Manager. Jan 1994, pp 66-67.

Hunter, R.R. and J.V. Morgan. 1989. Nutrition of strawberries in rockwool. Acta Horticulturea 238:127-134.

Iyer, C.P.A.; E.K. Chacko, and M.D. Subramaniam. 1979. Ethrel for breaking dormancy of strawberry seeds. Curr. Sci. 39:271-272.

John, M.K.; H.A. Daubeny, and F.D. McElroy. 1975. Influence of sampling time on elemental composition of strawberry leaves and petioles. J. Amer. Soc. Hort. Sci. 100(5):513-517.

Kader, A.A. 1991. Chap. 29: Quality and its maintenance in relation to the postharvest physiology of strawberry. Pp 145-152. In: A. Dale and J.J. Luby (eds). The strawberry into the $21^{\text {st }}$ century. Timber Press, Portland, OR, USA.

Lancaster, J.E., C.E.Lister, P.F. Reay, and C.M. Triggs. 1997. Influence of pigment composition on skin color in a wide range of fruit and vegetables. J. Am. Soc. Hort. Sci. 122(4): 594-598.

Larsen, M. and L. Poll. 1995. Changes in the composition of aromatic compounds and other quality parameters of strawberries during freezing and thawing. Z. Lebensm. Unters Forsch. 201:275-277.

Makus, D.J. and J.R. Morris. 1989. Influence of soil and foliar applied calcium on strawberry fruit nutrients and post-harvest quality. Acta Hort. 265: 443-446.

Makus, D.J. and J.R. Morris. 1998. Preharvest calcium applications have little effect on mineral distribution in ripe strawberry fruit. HortScience. 33(1): 64-66.

Manning, K. 1994. Changes in gene expression during strawberry fruit ripening and their regulation by auxin. Planta. 164: 62-68.

May, G. and M. Pritts. 1990. Strawberry nutrition. Adv. in Strawberry Production 9: 10-23.

McGuire, R.G. 1992. Reporting objective color measurements. HortScience 27(12):1254-1256. 
Miller, A.R.; J.C. Scheerens, P.S. Erb, and C.K. Chandler. 1992. Enhanced strawberry seed germination through in vitro culture of cut achenes. J. Amer. Soc. Hort. Sci. 117(2):313-316.

Morgan, J.V. 1985. Chap. 14: Ireland, current research and developments, pp116-122. In: A.J. Savage (ed). Hydroponics worldwide: state of the art is soilless crop production.

Nakamura, S. 1972. Germination of strawberry seeds. J. Jpn. Soc. Hort. Sci. 41:367-375.

Navarro, R.M.F., I Collados, C. Egea, and A.L. Alarcon. 1999. Development of colour in red pepper fruits in soilless culture. J. Hort. Sci. and Biotech. 74(2):175-180.

Neal J.C. and D.F. Wagner. 1983. Physical and chemical properties of coal cinders as a container media component. HortScience. 18(5): 693-695. Nonnecke, G.R. and M.L. Hayenga. 1991.Chap. 55: Consumer acceptance of locally grown dayneutral strawberries at an Iowa farmers' market. In: A. Dale and J.J. Luby (eds). The strawberry into the $21^{\text {st }}$ century. Timber Press, Portland, OR, USA.

Oda, Y. 1991. Chap. 2: The strawberry in Japan, pp 36-46. In: A. Dale and J.J. Luby (eds). The strawberry into the $21^{\text {st }}$ century. Timber Press, Portland, OR, USA.

Perez, A.G., C. Sanz, R. Olias, J.J. Rios, and J.M. Olias. 1996. Evolution of strawberry alcohol acyltransferase activity during fruit development and storage. J. Agric. Food Chem. 44: 3286-3290.

Perez, A.G., C. Sanz, R. Olias, and J.M. Olias. 1997. Effect of methyl jasmonate on in vitro strawberry ripening. J. Agric. Food Chem. 45: 3733-3737.

Perkins-Veazie, P. 1991. Chap. 37: Clues in the mystery of strawberry fruit ripening. In: A. Dale and J.J. Luby (eds). The strawberry into the $21^{\text {st }}$ century. Timber Press, Portland, OR, USA.

Poling, E.B. 1991. Chap. 54: The annual hill planting system for southeastern North Carolina, pp 258-263. In: A. Dale and J.J. Luby (eds). The strawberry into the $21^{\text {st }}$ century. Timber Press, Portland, OR, USA.

Renton, J. 1994. Report of ash analysis. Personal communication. West Virginia University, Morgantown, WV. 
Rosati, P. 1991. Chap. 1: The strawberry in Europe, pp27-35. In: A. Dale and J.J. Luby (eds). The strawberry into the $21^{\text {st }}$ century. Timber Press, Portland, OR, USA.

Sacks, E.J. and D.V. Shaw. 1994. Optimum allocation of objective color measurements for evaluating fresh strawberries. J. Amer. Soc. Hort. Sci. $119(2): 330-334$.

Scheerens, J.C. and G.L. Brenneman. 1991. Chapter 19: Fruit quality patterns based on decade of release or area of adaptation. pp 111-114. In: In: A. Dale and J.J. Luby (eds). The strawberry into the $21^{\text {st }}$ century. Timber Press, Portland, OR, USA.

Scott, D.H. and A.D. Draper. 1967. Light in relation to seed germination of blueberries, strawberries, and Rubus. HortScience 2:107-108.

Scott, D.H. and D.P. Ink. 1948. Germination of strawberry seed as affected by scarification treatments with sulfuric acid. Proc. Amer. Soc. Hort. Sci. 51:299-300.

Shaw. D.V. 1991. Genetic variation for objective and subjective measures of fresh fruit color in strawberries. J. Amer. Soc. Hort. Sci. 116(5):894-898.

Shaw, D.V. and E.J. Sacks. 1995. Response in genotypic and breeding value to a single generation of divergent selection for fresh fruit color in strawberry. J. Amer. Soc. Hort. Sci. 120(2):270-273.

Song, J.; L. Fan, and R.M. Beaudry. 1998. Application of solid phase microextraction and gas chromatography/time-of-flight mass spectrometry for rapid analysis of flavor volatiles in tomato and strawberry fruits. J. Agric. Food Chem. 46(9): 3721-3726.

Szczesniak, A.S. and B.J. Smith. 1969. Observations on strawberry texture, a three pronged approach. J. Textural Studies. 1: 65-89.

Thompson, P.A. 1969. The use of chilling and chemical treatments to promote rapid germination of strawberry achenes. J. Hort. Sci. 44:201-210.

Vaughn, S.F., G.F. Spencer, and B.S. Shasha. 1993. Volatile compounds from raspberry and Strawberry fruit inhibit postharvest decay fungi. J. of Food Sci. 58(4): 793-796.

Voss, D.H. 1992. Relating colorimeter Measurement of plant color to the Royal Horticultural Society Colour Chart. HortScience 27(12):1256-1260.

Walker, D.R. 1996. Personal communications. AgroDynamics, Ventura, CA. 
Wilhelm, S. and P.E. Nelson. 1970. A concept of rootlet health of strawberries in pathogen free field soil achieved by fumigation. Pp208-215. In: T.A. Toussoun, R.V. Bega, and P.E. Nelson (eds). Root diseases and soil borne pathogens. University of California Press, Berkeley.

Wilson, D.A.; A. Goodall, and J. Reeves. 1973. An improved technique for the germination of strawberry seeds. Euphytica 12:326-366.

Woodard, M.A.; B.C. Bearce, S.Cluskey, and E.C. Townsend. 1993. Coal bottom ash and pinewood peelings as root substrates in a circulating nutriculture system. HortScience 28(6): 636-638

Zabetakis, I. And M.A. Holden. 1997. Strawberry flavour: analysis and biosynthesis. J. Sci. Food Agric. 74:421-434. 


\section{APPENDIX I}

NUTRIENT SOLUTION USED FOR NUTRICULTURE PRODUCTION OF Fragaria $\mathrm{x}$ ananassa IN ROCKWOOL OR COAL BOTTOM ASH

Hydrosol (Peters Fert. Co.) plus calcium nitrate

\begin{tabular}{lr}
\hline nutrient & mg. - $^{-1}$ \\
\hline $\mathrm{N}$ & 150 \\
$\mathrm{P}$ & 48 \\
$\mathrm{~K}$ & 210 \\
$\mathrm{Ca}$ & 150 \\
$\mathrm{Mg}$ & 30 \\
$\mathrm{SO} 4$ & 117 \\
$\mathrm{Fe}$ & 3 \\
$\mathrm{Mn}$ & 0.50 \\
$\mathrm{Zn}$ & 0.15 \\
$\mathrm{Cu}$ & 0.15 \\
$\mathrm{~B}$ & 0.50 \\
$\mathrm{Mo}$ & 0.10 \\
$\mathrm{Cl}$ & 0.04 \\
$\mathrm{Na}$ & 3.619 \\
\hline
\end{tabular}

Mix $=184$ g Hydrosol +122 g calcium nitrate +189.3 L steam distilled water $\mathrm{K}: \mathrm{N}$ ratio $=1.4: 1$

COMPARISON OF Sarooshi and Cresswell, 1994 SIMPLE GROW STRAWBERRY MIX

\begin{tabular}{lr}
\hline nutrient & $\mathrm{mg} \cdot \mathrm{L}^{-1}$ \\
\hline $\mathrm{NO} 3$ & 138 \\
$\mathrm{NH} 4$ & 35 \\
$\mathrm{PO} 4$ & 36 \\
$\mathrm{~K}$ & 292 \\
$\mathrm{Ca}$ & 95 \\
$\mathrm{Mg}$ & 30 \\
$\mathrm{Fe}$ & 6 \\
$\mathrm{Mn}$ & 0.45 \\
$\mathrm{Zn}$ & 0.20 \\
$\mathrm{Cu}$ & 0.17 \\
$\mathrm{Cl}$ & 17 \\
$\mathrm{Na}$ & 14 \\
\hline
\end{tabular}

$\mathrm{K}: \mathrm{N}$ ratio $=1.7: 1$

Topping up solution $=250 \mathrm{~g} \mathrm{Ca}(\mathrm{NO} 3) 2.4 \mathrm{H} 2 \mathrm{O}+25 \mathrm{~g}$ NH4NO3 $+2 \mathrm{~kg}$ stock solution

giving $121 \mathrm{mg} \cdot \mathrm{L}^{-1}$ calcium, $25 \mathrm{mg} \cdot \mathrm{L}^{-1}$ ammonium, and $208 \mathrm{mg} \cdot \mathrm{L}^{-1}$ nitrate for a $\mathrm{K}: \mathrm{N}$ ratio of $1.4: 1$. 


\section{APPENDIX II}

NITRIC ACID MICROWAVE DIGESTION PROCEDURE FOR LEAF TISSUE ANALYSIS OF Fragaria $\mathrm{x}$ ananassa

Reagent: HNO3 (70\%)

Procedure:

1. Weigh $0.5 \mathrm{~g}$ of dried ground sample into each microwave vessel

2. Add $10 \mathrm{ml}$ of $\mathrm{HNO} 3$ to each vessel

3. Seal all vessels except the one to be used for the pressure control (this must contain the largest and most reactive of the samples)

4. Seal the control vessel with the modified cap assembly

5. Place the vessels into the turntable. Connect the vent tube from the vessel to the collection vessel.

6. Place the turntable into the microwave. Connect the pressure sensing line to the control vessel.

7. Program the microwave for:

\begin{tabular}{cccccc}
\hline Stage & 1 & 2 & 3 & 4 & 5 \\
\hline$\%$ power & 100 & 100 & 100 & 0 & 0 \\
PSI & 40 & 80 & 120 & 0 & 0 \\
Time & $10: 00$ & $15: 00$ & $20: 00$ & 0 & 0 \\
TAP & $5: 00$ & $8: 00$ & $10: 00$ & 0 & 0 \\
Fan speed & 100 & 100 & 100 & 100 & 100 \\
\hline
\end{tabular}

8. Run the heating program to completion

9. Cool the samples for a minimum of 5 minutes

10. Vent the control vessel and remove the pressure sensing line.

Remove the turntable from the system.

11.Manually vent and open the vessels in the fume hood. Allow to cool.

12. Filter samples with Whatman's 42 ashless filter paper and dilute 1:10 for ICP analysis of nutrient levels. 


\section{APPENDIX III}

\section{PROBLEMS ENCOUNTERED}

In the first 'Fresca' nutriculture study we developed a series of leaks in the drainage system. These created difficulty in maintaining the recirculation stock tanks with a common replacement quantity, so that some tanks received fresh nutrient solution more often than the others.

Second nutriculture 'Fresca' study was established in room 2C of the greenhouse with individual pots, supported in a grid of re-bar, with drip emitters and individual effluent catch lines. This worked well. Unfortunately the plants became infested with mealy bugs, which migrated to the petiole base (which wraps the stem) and were impossible to clean out. Over half of the plants succumbed to the mealy bugs, resulting in plant death.

The area was cleaned up, and the cultivars were planted and the nutriculture study started. Most of the 'Kent' and 'Annapolis' plants were lost early in the study.

For flavor analysis, fruits were collected and placed into specimen containers. The containers were then punctured with a hypodermic needle and headgases removed. The gases were then stored in vacutubes and held in the refrigerator. The gas samples were collected in this manner for 3 time periods for each fruit over a 9 month period of time. Unfortunately, these samples were not concentrated enough and no aroma peaks were measureable by our GC. This left the fruit that had been frozen as a backup to be analyzed for flavor/aroma compounds. The total amount of fruit that had been used for the first gas collection left limited amounts for the backup. The resulting extraction and analysis base material was limited and the extractions could not be replicated as they should have been. Also with the extraction/concentration of aroma compounds, I was unable to set up a 
nitrogen flow for removing the ether:pentane solution and used the rotary evaporator instead. Although the temperatures were kept as low as possible in the lab, several of the more volatile compounds no doubt were removed at the same time as the ether:pentane.

For future studies, it would be advisable to create a hood designated for the specific purpose of aroma collection and concentration apparatus. Working with the newly developed solid phase micro extraction fibers would be ideal, however, would require retro-fitting the $\mathrm{GC}$ with the appropriate column loading port. For identification of the individual flavor compounds the GC would need to be associated with a mass spectrometer and a different GC column used, due the bleed over of the carbowax from the column used in this study onto the mass spec. 


\section{Vitae}

Donna Ballard

\section{EDUCATION}

Doctor of Philosophy, specialization Horticulture, 2000

West Virginia University, Morgantown, WV

Dissertation: Strawberry growth and fruit characteristics in response to coal bottom ash root media.

Master of Science, specialization Horticulture, 1993

West Virginia University, Morgantown, WV

Thesis: Horticultural crop production on surface minesoil amended with municipal sewage sludge, hardwood residues, or a green manure crop

Bachelor of Science Landscape Architecture, 1985

West Virginia University, Morgantown, WV

Senior project: Redevelopment of the Seneca Area, a glass workers community of Morgantown, WV.

\section{EMPLOYMENT}

West Virginia University, Morgantown, WV, Aug 1993 to present

Research Assistant, Div. of Plant and Soil Sciences, for Dr. Kotcon

Coordinate farm management plan, maps, planting, harvesting, and data collection with field and laboratory work, data analysis, and record keeping for transitioning from conventional to organic farm research

Visiting Lecturer, Dept. of Horticulture, instructor for Hort 242 - Small Fruits

Visiting Lecturer, Dept. of Horticulture, instructor for Hort 245 - Greenhouse Management

Visiting Lecturer, Dept. of Horticulture, instructor for Hort 246 - Tree Fruits Graduate Research assistant, Dept. of Horticulture, for Dr. Bradford C. Bearce Laboratory, greenhouse, and field research projects with surface mine reclamation and greenhouse production of horticultural crops

Free-lance landscape designer, Morgantown, WV, Aug 1988 to May 1991

Rich Farms, Whitehouse, PA, Nov to Dec 1998

Consultant for Wholesale Nursery development

Rich Farms, Whitehouse, PA, May 1991 to June 1993

Garden center and nursery salesperson

Landscape designer

Landscape installation supervisor

Personnel and management consultant

West Virginia University, Morgantown, WV, May 1991 to May 1993

Graduate Research assistant, Dept. of Horticulture, for Dr. Bradford C. Bearce

Laboratory, greenhouse, and field research with surface mine reclamation emphasis 